\title{
Interplay Between Oxidative and Carbonyl Stresses: Molecular Mechanisms, Biological Effects and Therapeutic Strategies of Protection
}

\author{
Halyna M. Semchyshyn and Volodymyr I. Lushchak \\ Vassyl Stefanyk Precarpathian National University, \\ Ukraine
}

\section{Introduction}

Reactive species (RS) are continuously produced and eliminated in variuos groups of organisms: from bacteria to man. Under normal physiological conditions, the steady-state concentrations of RS are maintained at certain range and fluctuate similarly to other parameters in the organism according to homeostasis theory. The persistence of RS in cells demonstrates their evolutionarily selected production in order to perform some useful role in living organisms. The most beneficial among important biological roles of RS is their establishment as important regulators of cell signal transduction and part of immune response controlling cellular defense against various environmental challenges.

However, under some circumstances, RS level may leave the range of normal concentrations due to change of their production or change of efficiency of catabolic system. An increase in steady-state level of reactive oxygen species (ROS) or reactive carbonyl species (RCS) may result in so-called "oxidative stress" or "carbonyl stress", respectively. Generally, ROS and RCS are mainly known for their damaging effects. At molecular level, they are found to disrupt the structure and function of proteins, nucleic acids, lipids, carbohydrates, etc. As a consequence of these undesirable effects at cellular and organismal levels, loss of function and even viability can occur.

Recent studies indicate that in many cases increase in RCS steady-state concentrations is a consequence of oxidative stress, whereas increase in ROS steady-state levels is resulted from carbonyl stress. Thus, a vicious cycle can be formed.

Carbonyl/oxidative stress has been found to be implicated in many chronic and degenerative diseases. Different metabolic disorders, diabetes, obesity, kidney and heart diseases, atherosclerosis, and neurodegenerative diseases all have a strong component of carbonyl/oxidative stress. It is unclear however, whether the carbonyl/oxidative stress is causal in disease progression or the result of the cell death associated with cells dying by apoptosis or necrosis.

\section{Reactive carbonyl compounds}

Reactive carbonyls are commonly generated in vivo as metabolic products (Tessier, 2010; Turk, 2010; Peng et al., 2011; Robert, 2011) or derived from the environment (Uribarri and 
Tuttle, 2006; Birlouez-Aragon et al., 2010; Uribarri et al., 2010). Similarly to other RC, RCS can play a dual role in living organisms. For instance, some RCS are implicated as signalling molecules controlling cellular defense against the environmental challenges. On the other hand, due to high reactivity RCS interact with different cellular constituents that may contribute to aging, age-related diseases, and diverse metabolic disorders.

\subsection{Structure and reactivity}

RCS is a large group of reactive biological molecules mainly with three to nine carbons in length containing one or more carbonyl groups. Most of the biological damages caused by RCS are related to $\alpha, \beta$-unsaturated aldehydes, dialdehydes, and keto-aldehydes (Uchida, 2000; Pamplona, 2011). Figure 1 demonstrates the most common RCS found in biological systems. Malondialdehyde (MDA), glyoxal (GO), methylglyoxal (MGO), glucosone, 3deoxyglucosone (3DG), and ribosone are among highly reactive $\alpha-$ and $\beta$-dicarbonyl compounds. Acrolein, crotonaldehyde and 4-hydroxy-trans-2-nonenal (HNE) belong to $\alpha, \beta-$ unsaturated aldehydes. One of the most biologically important keto-aldehydes is 4-oxotrans-2-nonenal (ONE). Glycolaldehyde, dehydroascorbate, acetaldehyde, glceraldehyde-3phosphate and dioxyacetone phosphate are also among the reactive carbonyls ubiquitously generated in biological systems.<smiles>C=CC=O</smiles>

acrolein<smiles>CC(=O)C=O</smiles><smiles>O=CC(=O)C(O)C(O)C(O)CO</smiles>

glucosone<smiles>CCCCCC(=O)/C=C/C=O</smiles>

4-oxo-trans-2-nonenal<smiles>CCCCCC(O)/C=C/C=O</smiles>

4-hydroxy-trans-2-nonenal<smiles>O=CCC(=O)OC(=O)C(O)C(O)CO</smiles>

ribosone<smiles>O=CC(=O)CC(O)C(O)CO</smiles>

3-deoxyglucosone

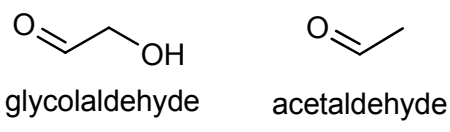<smiles>O=C1OC(C(O)CO)C(=O)C1=O</smiles>

dehydroascorbate

Fig. 1. The structures of the most common biological reactive carbonyl species. 
It should be noted that unsaturated RCS are usually an order of magnitude more reactive than their saturated counterparts. $\alpha, \beta$-Unsaturated carbonyls are especially reactive, because they have carbonyl group and reactive double bond that makes the $C_{3}$ carbon a strong electrophile. Extremely reactive carbonyl compound is HNE which possesses electrophilic double bond, carbonyl and hydroxyl groups. However, such dialdehydes as GO, MGO, and 3-DG are much more active than HNE and MDA (Lankin et al., 2007). In addition, acrolein reacts with thiols 100-fold more rapidly than HNE (Witz, G. 1989, Esterbauer et al., 1991). Like hydroxyl radical is the most powerful oxidant among ROS, acrolein is the most electrophilic, and therefore reactive $\alpha, \beta$-unsaturated aldehyde known.

Carbonyl compounds like most other intermediates and by-products of metabolism are electrophilic, and thus are highly reactive with different cellular constituents majority of which are nucleophiles (Zimniak, 2011). Such strong nucleophilic sites as thiol, imidazole, and hydroxyl groups of biomolecules as well as nitrogen and oxygen atoms in purine and pyrimidine bases are the most attractive targets for electrophilic attacks. In general, all mentioned above interactions may lead to chemical modification of proteins, nucleic acids, and aminophospholipids, resulting in cytotoxicity and mutagenicity (Ellis, 2007; Liu et al., 2010). Sience biological effects caused by RCS and ROS are rather similar, chemical properties of both groups seem should be similar as well. However, RCS have a relatively long half life time and therefore higher stability, in contrast to ROS. For instance, reactive carbonyls have average half-life from minutes to hours (Uchida, 2000; Pamplona, 2011). At the same time, half-life of some ROS ranges from $10^{-9}$ to $10^{-6} \mathrm{~s}$ (Halliwell and Gutteridge, 1989; Demple, 1991). It is well known that non-charged ROS such as $\mathrm{H}_{2} \mathrm{O}_{2}$ and $\mathrm{HO}_{2}{ }^{*}$ are capable to cross biological membranes and diffuse for relatively long distances in the intracellular environment. At the same time, higher stability of non-charged RCS molecules allows them even to escape from the cell and interact with targets far from the site of their generation. That is why, under certain conditions, RCS may have far-reaching damaging effects, and therefore they can be more deleterious than ROS.

\subsection{Generation in vivo}

Carbonyl compounds can be endogenous or exogenously derived. Some RCS (e.g. acrolein, crotonaldehyde, acetone and formaldehyde) are ubiquitous industrial pollutants which can readily enter the cell from the environment (Trotter et al., 2006; Liu et al., 2010; Seo and Baek, 2011). Other exogenous sources of reactive carbonyls are products of organicpharmaceutical chemistry, cigarette smoke, food additives and browned food (Uribarri et al., 2007; Birlouez-Aragon et al., 2010; Colombo et al., 2010; Dini, 2010; Robert et al., 2011). Number of carbonyl compounds is formed under chemical modification of the nutrients during food cooking (browning, Maillard reaction). The browning reaction between amino acids and simple carbohydrates was first observed a century ago by Louis Camille Maillard (Maillard, 1912). About 40 years later Maillard reaction was recognized as one of the main reasons for the occurrence of the non-enzymatic food browning demonstrating an importance in food science (Hodge, 1953; Tessier, 2010). In late 1960s, the products of a nonenzymatic glycosylation similar to the food browning were detected in human organism (Rahbar, 1968; Rahbar et al., 1969). Thus, it took several decades to realize the physiological significance of the reaction discovered by Maillard. In 1980s, the in vivo reaction between biomolecule amino groups and monosaccharides, without enzymes, was named "nonenzymatic glycosylation" and several years later renamed "glycation" in order to 
differentiate it from the enzymatic glycosylation important in the post-translation modification of proteins (Yatscoff et al., 1984). Now it is well documented that glycation is one of the most significant endogenous sources of reactive carbonyls (Tessier, 2010).

More than 20 saturated and unsaturated RCS have been identified in biological samples (Niki, 2009). Table 1 demonstrates that, in general, endogenous RCS can be formed as products of either enzymatic or non-enzymatic processes.

\begin{tabular}{|l|l|l|l|l|}
\hline Enzymatic sources & Non-enzymatic sources \\
\hline Glycolysis & Polyol pathway & $\begin{array}{l}\text { Oxidation of amino } \\
\text { acids }\end{array}$ & Glycation & Peroxidation of lipids \\
\hline $\begin{array}{l}\text { Acetaldehyde } \\
\text { Glyceraldehyde-3-Deoxyfructose } \\
\text { 3-phosphate } \\
\begin{array}{l}\text { Dioxyacetone } \\
\text { phosphate } \\
\text { Methylglyoxal }\end{array}\end{array}$ & $\begin{array}{l}\text { 3-Deoxyglucosone } \\
\text { Glyoxal } \\
\text { Methylglyoxal } \\
\text { Acrolein }\end{array}$ & $\begin{array}{l}\text { Glyoxal } \\
\text { Methylglyoxal } \\
\text { Glycolaldehyde } \\
\text { 2-Hydroxypropanal }\end{array}$ & $\begin{array}{l}\text { Glucosone } \\
\text { 3-Deoxyglucosone } \\
\text { Acrolein }\end{array}$ & $\begin{array}{l}\text { M-Hydroxy-trans-2- } \\
\text { nonenal } \\
\text { 4-Oxo-trans-2-nonenal } \\
\text { Glyoxal } \\
\text { Methylglyoxal } \\
\text { Acrolein } \\
\text { Crotonaldehyde } \\
\text { Hexanal }\end{array}$ \\
\hline
\end{tabular}

Table 1. Reactive carbonyl species and sources of their generation in vivo

In this section, we will describe common ways of RCS generation in vivo, in particular, polyol pathway, amino acid oxidation, lipid peroxidation, and glycation.

\subsubsection{Enzymatic reactions}

Reactive carbonyls are produced intracellularly through both enzymatic and non-enzymatic pathways. Enzymatically produced RCS, glycolytic intermediates or by-products of metabolic conversion of carbohydrates and amino acids, are presented in Table 1 . The effective steady-state concentration of such metabolites as acetaldehyde, glyceraldehyde-3phosphate and dioxyacetone phosphate is typically low in the cell, because of their rapid utilization by the next step of the pathway (Zimniak, 2011). However, concentration of MGO, a by-product of glycolysis in most living organisms, is not so tightly controlled. Therefore, under certain conditions, biological effects of MGO may be more potent than the effect caused by the glycolytic intermediates.

The elimination of phosphate from glyceraldehyde-3-phosphate and dihydroxyacetone phosphate is the major enzymatic source of MGO in vivo (Pompliano et al., 1990; Phillips and Thornalley, 1993; Richard, 1993). In Figure 2 the mechanism of the reaction is given. As seen, enediol phosphate, an intermediate in the above mentioned reactions, may escape from the active site of triosophosphate isomerase and be rapidly decomposed to MGO and inorganic phosphate (Pompliano et al., 1990). MGO can also be formed from hydroxyacetone, an intermediate in the enzymatic oxidation of ketone bodies (Lyles and Chalmers, 1992; Turk, 2010). Oxidation of some amino acids can also lead to MGO formation under physiological conditions. For example, threonine and glycine can be converted to aminoacetone and succinylacetone, MGO precursors (Kalapos, 2008a). It should be noted 
<smiles></smiles>

Dioxyacetonphosphate

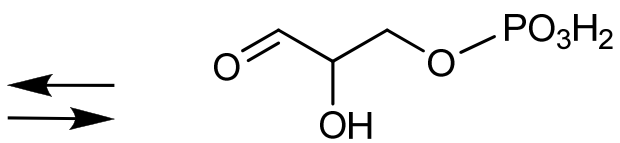

Glyceraldehyde-3-phosphate

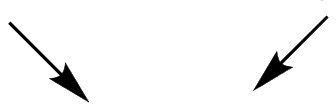<smiles>O/C=C(\O)O[Pb]</smiles>

Enediol phoshate (intermediate)<smiles>CC(=O)C=O</smiles>

\section{Methylglyoxal}

Fig. 2. Formation of methylglyoxal as a by-product of glycolysis.

that MGO can be formed from dihydroxyacetone phosphate in the reaction catalysed by bacterial MGO synthase, however, it is unknown whether this enzyme and this kind of MGO generation also exist in animals (Kalapos, 2008b).

Polyol pathway may be associated with the production of 3-DG one more carbonyl compound ubiquitously generated in biological systems (Niwa, 1999; Chung et al., 2003). The mechanism of its generation is demonstrated in Figure. 3. In one way, 3-DG is formed from fructose, an oxidized product of sorbitol by sorbitol dehydrogenase. In the second one, 3-DG is a hydrolysis product of fructose-3-phosphate, an enzymatic product of fructose phosphorylation. Further enzymatic reduction and oxidation of 3-DG can result in 3deoxyfructose and 2-keto-3-deoxygluconic acid formation, respectively (Niwa, 1999).

Different RCS can be generated in vivo by activated human phagocytes. It has been found that stimulated neutrophils employed the myeloperoxidase- $\mathrm{H}_{2} \mathrm{O}_{2}$-chloride system to produce $\alpha$-hydroxy and $\alpha, \beta$-unsaturated aldehydes from hydroxy-amino acids in high yield (Anderson et al., 1997). Figure 4 shows possible mechanism of glycolaldehyde formation from L-serine, and acrolein from L-threonine.

In conclusion, in vivo detection of enzymatically produced RCS is still quite complicated task, because of their relatively low stability under physiological conditions. It seems, more endogenous sources of RCS would be described with using sophisticated techniques in not far future. 


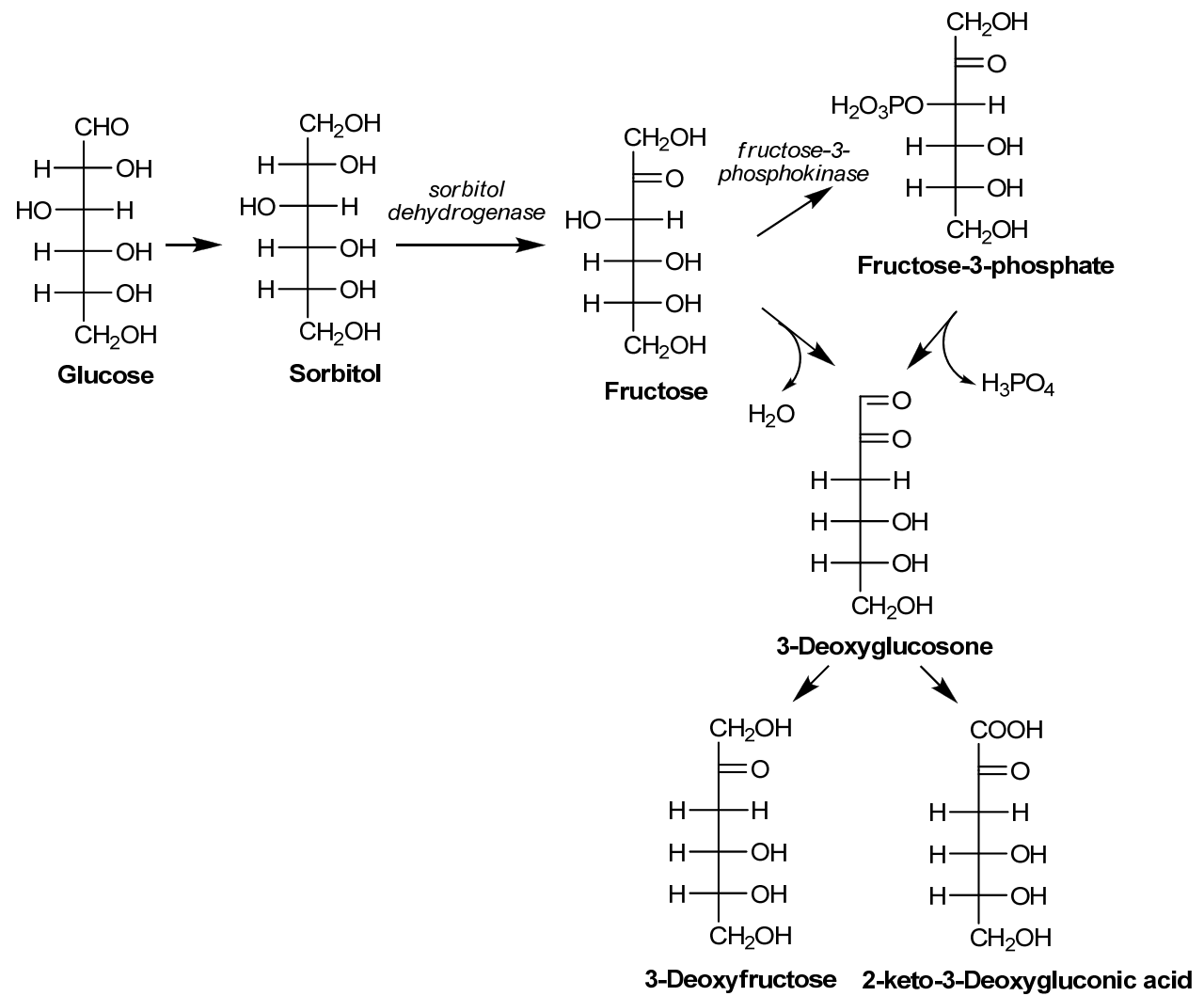

Fig. 3. Polyol pathway as a source of formation of reactive carbonyl species.<smiles>NC(CO)C(=O)OCCO</smiles>

Serine<smiles>O=CCO</smiles>

Glycolaldehyde<smiles>CC(O)C(N)C(=O)O</smiles>

Threonine<smiles>C=CC(=O)OCC(C)O</smiles>

2-Hydroxypropanal

Acrolein

Fig. 4. Possible mechanisms of glycolaldehyde and acrolein generation by activated neutrophils.

\subsubsection{Non-enzymatic reactions}

Non-enzymatic reactions, bypassing the classic metabolic pathways, play a crucial role in RCS generation in vivo. A numerous literature reveals that oxidative degradation of biomolecules is the major way in the non-enzymatic production of RCS. For instance, degradation of nucleic acids and related compounds results in the formation of reactive carbonyls. In model experiments, it was demonstrated that purified RNA, DNA, and their precursors contribute to MGO formation (Chaplen et al., 1996). However, probably because of the higher intracellular steady-state concentrations of lipids, proteins and carbohydrates as compared with nucleic acids, oxidative catabolism of lipids, amino acids and 
carbohydrates is believed to be the major source of endogenous non-enzymatically produced RCS (Uchida, 2000).

\subsubsection{Lipid peroxidation}

In 1930s, lipid peroxidation (LPO) was first studied in relation to food deterioration (Niki, 2000). Later investigations revealed that LPO products can be formed in living organisms. Similarly to the Maillard reaction, with increased evidences on physiological significance of the process, several decades later LPO received renewed attention in biochemistry, and medicine.

It is well known that different mechanisms underlie LPO process: (i) enzymatic oxidation, (ii) ROS-independent nonenzymatic oxidation, and (iii) ROS-mediated nonenzymatic oxidation (Niki 2009). Due to various mechanisms, specific LPO products can be formed. There are many evidences that reactive carbonyls are produced through LPO as a consequence of oxidative stress (Ellis, 2007; Negre-Salvayre et al., 2008; Pamplona, 2008; Zimniak, 2008; Pamplona, 2011; Zimniak, 2011). LPO induced by ROS generates a variety of primary, secondary and end products (Figure 5).

Oxidation of polyunsaturated fatty acids (PUFAs), which are highly susceptible to peroxidation by ROS, involves an allylic hydrogen abstraction to form a tetradienyl radical $\left(\mathrm{L}^{\cdot}\right)$ followed by insertion of molecular oxygen. Addition of oxygen results in peroxyl radical formation (LOO*), which is further transformed to hydroperoxide ( $\mathrm{LOOH}$ ) by hydrogen abstraction from another lipid molecule $(\mathrm{LH})$. The latter gives another free radical $\left(\mathrm{L}^{\bullet}\right)$ and propagates oxidation. All radical compounds appeared from oxidation of lipids belong to primary LPO products, and lipid hydroperoxides (LOOH) are named as secondary LPO products. In addition, peroxyl radical (LOO•) can undergo further oxidation to form other highly oxidized products such as bicyclic endoperoxides, monocyclic peroxides, serial cyclic peroxides and other complex peroxides (Yin et al., 2002). Most of them are unstable and can be readily decomposed to so-called LPO-derived end products, a wide array of compounds, including RCS (Esterbauer et al. 1991). The most common reactive carbonyls derived from PUFA oxidation are MDA, hexanal and HNE, comprising of $70 \%, 15 \%$, and $5 \%$ of the total produced by lipid peroxidation, respectively (Ellis, 2007). Acrolein was identified as a LPO end product at oxidation of low density lipoproteins (Ellis, 2007).

As mentioned above, reactive carbonyls, end LPO products, can react with nucleophilic groups in biomolecules resulting in their irreversible modifications and formation of a variety of adducts and cross-links collectively named advanced lipoxidation end products (ALEs). In turn, ALEs may lead to ROS formation, and as a consequence, propagation of oxidative modifications.

\subsubsection{Glycation (Maillard chemistry)}

Glycation is a complex series of parallel and sequential reactions, in which reducing free carbonyl groups of carbohydrates react with the nucleophilic amino groups of biomolecules, producing a large number of variuos compounds, including RCS (Finot, 1982; Ellis, 2007; Tessier, 2010; Peng et al., 2011; Robert, 2011). The initial step of glycation, the Maillard reaction, is the covalent interaction between reducing monosaccharide (e.g. glucose, fructose, galactose, glucose-6-phosphate) and N-terminal amino acid residues or epsilon amino groups of proteins, lipids, and nucleic acids, which produces an acyclic form of Schiff base rearranging reversibly to cyclic $\mathrm{N}$-substituted glycosylamine (Figure 6). 


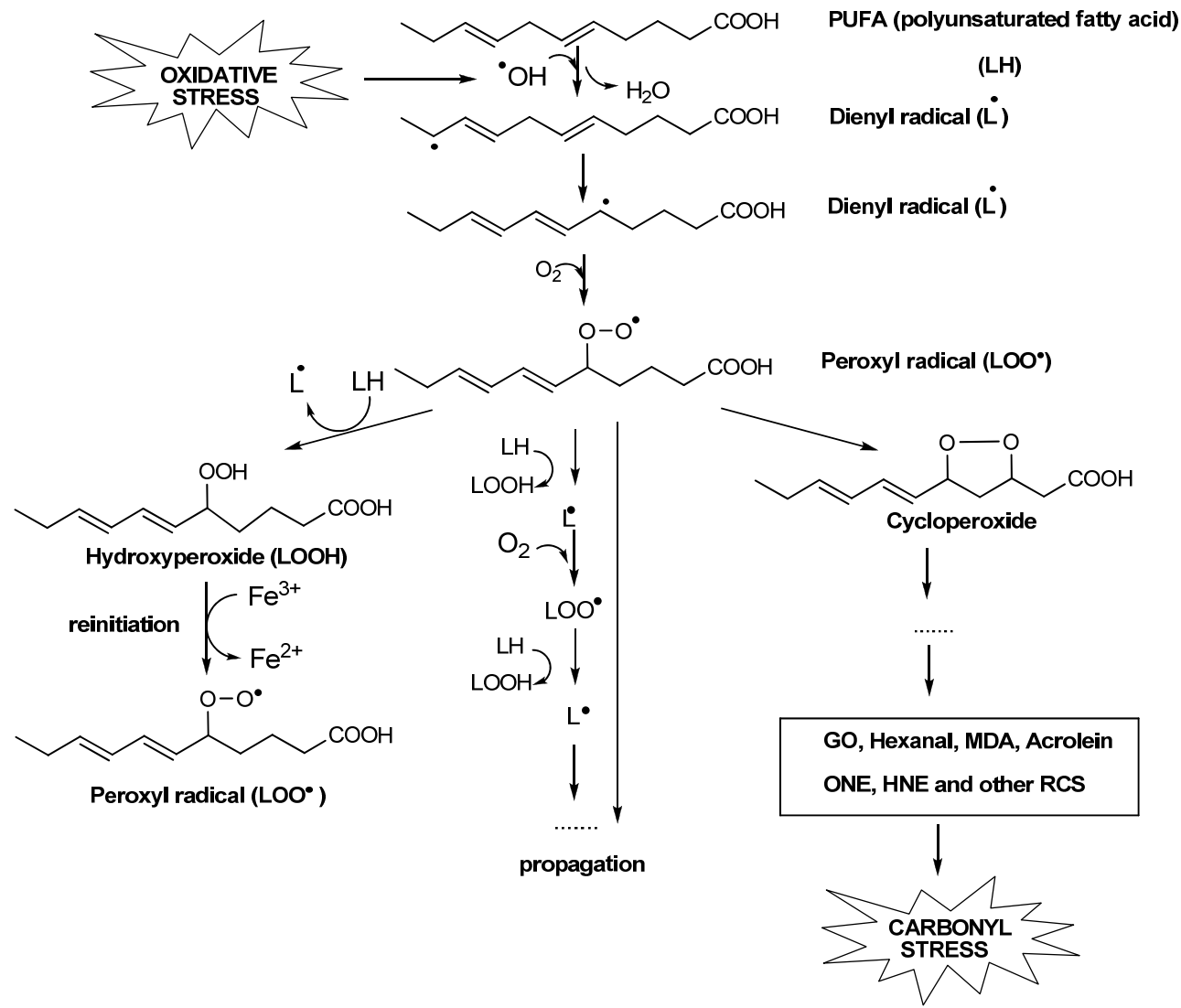

Fig. 5. Suggested pathways of lipid peroxidation and its relation to oxidative and carbonyl stresses (modified from (lushchak et al., 2011c)).

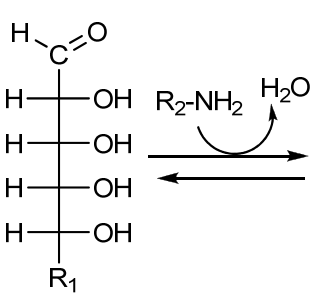

Reducing monosaccharide

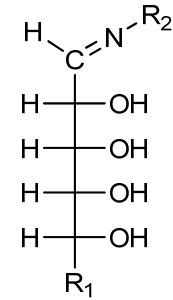

Shiff base

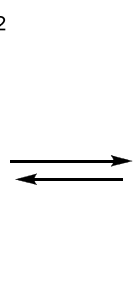

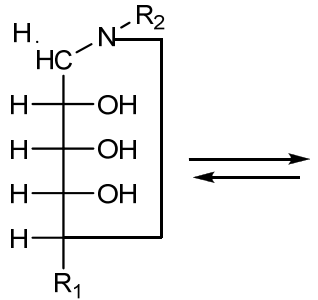<smiles>[R2]NCC(=O)C(O)C(O)C([R1])O</smiles>

Amadori compounds (ketosamines, early glycation products)

Fig. 6. Formation of Amadori products in the Maillard reaction.

The latter is an unstable compound, which can be subjected to further isomerization called an Amadori rearrangement giving more stable Amadori adducts (early glycation products), 
namely ketosamines. Amadori products derived from non-enzymatic glycation by hexoses are commonly known as "fructosamine". The carbohydrate moiety of Amadori products can undergo enolization, followed by dehydration, oxidation and/or fragmentation reactions, consequently producing a variety of RCS, including GO, MGO, glucosone, 1-, 2- and 3deoxyglucosones, 3,4-dideoxyglucosone, erythrosone, ribosone, 3-deoxyerythrosone, and 3-deoxyribosone (Reihl et al., 2004; Thornalley, 2005; Tessier, 2010). Figure 7 shows the mechanism of glucosone formation followed by generation of such ROS as superoxide and hydrogen peroxide.

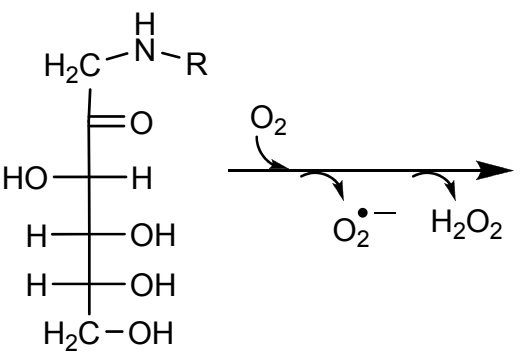

Amadori Compound<smiles>[R]CNC[C@@H](O)[C@@H](O)[C@H](O)[C@H](O)CO</smiles>

Glucosone

Fig. 7. Formation of glucosone from the Amadori compound.

In addition, there is an evidence for the fragmentation of the Schiff base, leading to the formation of GO, MGO, and hydrogen peroxide (Figure 8) (Hayashi and Namiki, 1980; Namiki and Hayashi, 1983). The series of reaction pathways in Maillard chemistry established Shiff base fragmentation to a-oxoaldehydes now collectively called the Namiki pathway (Thornalley, 2005; Peng et al., 2011).

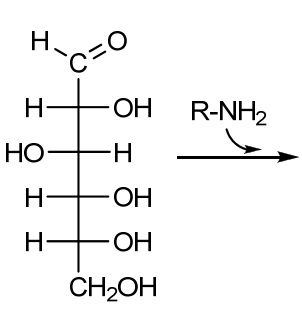

Glucose

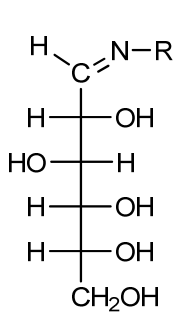

Shiff base
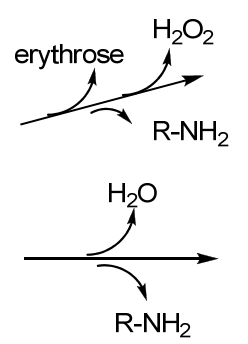

$\mathrm{R}-\mathrm{NH}_{2}$
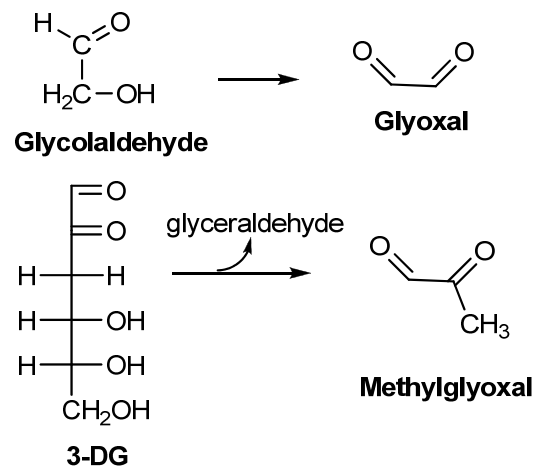

Fig. 8. Namiki pathway.

Slow oxidative degradation of monosaccharides under physiological conditions leads to the formation of a-oxoaldehydes and hydrogen peroxide (Figure 9) (Thornalley et al., 1984; Wolff et al., 1991). This process was called monosaccharide autoxidation or Wolff pathway (Peng et al., 2011). The complicity of glycation with all variety of substrates and products, and almost unpredictable direction of the process is similar to free-radical chain reactions, in 
particular LPO. That is why the term "Maillard chemistry" is widely used to describe a variety of chemical reactions involved in the glycation processes.<smiles>CCC(O)C(O)C(O)C(O)C(O)C(O)C(O)C(O)CO</smiles>

Glucose

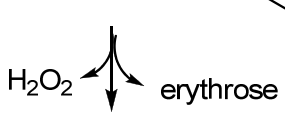<smiles>O=CCO</smiles>

Glycolaldehyde<smiles>O=CC=O</smiles>

Glyoxal

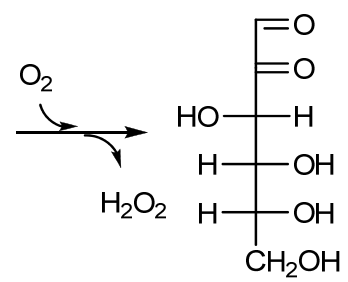

Glucosone

Fig. 9. Wolff pathway.

In the late stage of glycation, these reactive a-oxoaldehydes as well as Amadori compounds again interact with free amino, sulfhydryl and guanidine functional groups of intracellular and extracellular biomolecules leading to crosslinking and formation of advanced glycation end products (AGEs) (Peng et al., 2011; Robert, 2011). Therefore, Amadori products and RCS formed during glycation are believed to be important precursors of glycation adduct formation in biological systems.

\subsubsection{Advanced lipooxidation and glycation end products}

As seen in the above sections, LPO and glycation are complexes of very heterogeneous chemical reactions, leading to the formation of low molecular mass RCS. Further, these RCS, being either LPO end products or glycation intermediates, react with nucleophilic groups of macromolecules like proteins, nucleic acids, and aminophospholipids, resulting in their nonenzymatic, and irreversible modification and formation of a variety of adducts and crosslinks collectively named ALEs and AGEs (Figure 10) (Miyata et al., 2000; Ellis, 2007; Tessier, 2010; Pamplona, 2011; Peng et al., 2011).

It is well documented that LPO-derived RCS reacting with proteins produce such ALEs as MDA-Lys, HNE-Lys, propanal-His, propenal-Lys, and S-carboxymethyl-cysteine, as well as such cross-link as MDA-lysine dimmer, among many others (Figure 11) (Uchida et al., 1997; Shao et al., 2005; Pamplona, 2008 and 2011). 


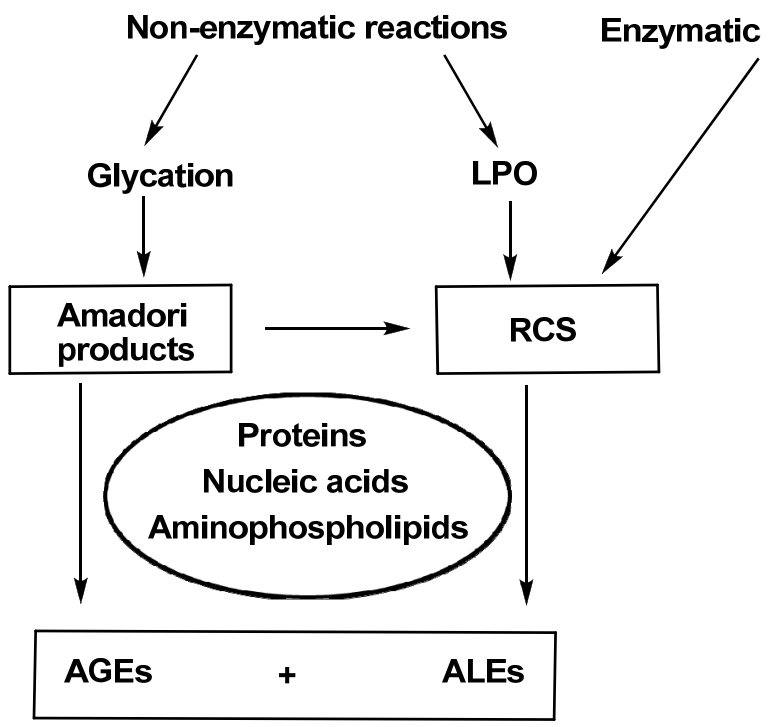

Fig. 10. Formation of reactive carbonyls and advanced glycation and lipoxidation end products in enzymatic and non-enzymatic processes.

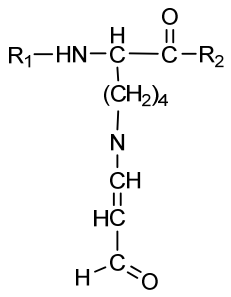

Propenal-Lys

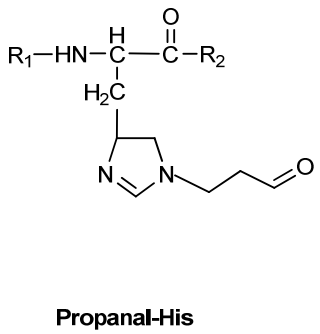

Propanal-His

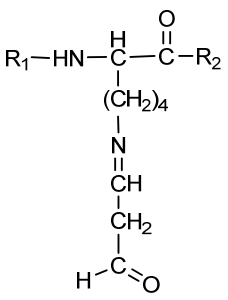

MDA-Lys<smiles>[R]C(=O)C([R])CNC1CC(O)OC1CCCCC</smiles>

HNE-Lys<smiles>[AsH3]N=CC=CN[AsH3]</smiles>

Lys-1-amino-3-iminopropene-Lys (MDA-lysine dimmer)

Fig. 11. The structures of the most common biological advanced lipoxidation end products.

LPO end products can also interact with amino groups of deoxyguanosine, deoxycytosine, guanosine to form various alkylated products (Pamplona, 2008). Those are the most common targets for RCS. Interaction between RCS and amino groups of aminophospholipids results in the formation of adducts like MDA-phosphatidylethanolamine, and carboxymethylphosphatidylethanolamine (Pamplona, 2008).

Extensive study of AGEs has revealed many stable end-stage adducts derived from the interactions between glycation-derived RCS and biomolecules. For instance, glycation intermediates have been demonstrated to react with guanidine groups of arginine residues, 
giving arginine-derived advanced glycation adducts: hydroimidazolones, argpyrimidine and $\mathrm{N} \omega$-carboxymethylarginine (Thornalley, 2005). Investigation of importance of glycolysis intermediates in the Maillard reaction has shown the formation of lisyl-hydroxy-triosidine and arginyl-hydroxy-triosidine during incubation of glyceraldehyde and glyceraldehyde-3phosphate with N-alpha-acetyl lysine and N-alpha-acetyl arginine (Tessier et al., 2003). In addition, dihydroxyacetone can also form crosslinking triosidines. Acetaldehyde was shown to react rapidly with proteins, producing deep red macromolecular acetaldehyde-protein condensates (Robert et al., 2010). Among common AGEs found in a biological material are such compounds linking lysine and arginine as fluorescent pentosidine, and non-fluorescent glucosepan (Peyroux and Sternberg, 2006). The structural similarity of glucosepan and pentosidine (Figure 12) makes it obvious some parallelism in the respective pathways of their production.

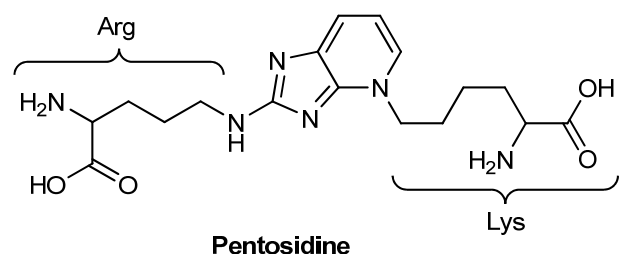

Pentosidine<smiles>NC(CCCCN1CC(O)C(O)CC2=NC(NCCCC(N)C(=O)O)=NC21)C(=O)O</smiles>

Glucosepan

Fig. 12. The structures of the most common biological advanced glycation end products.

Physiological processes leading to ALE and AGE formation also involve chemical modifcation of biomolecules by GO and MGO derived from both LPO and glycation processes. Non-fluorescent crosslinks such as GO-lysine dimmer (GOLD) and MGO-lysine dimmer (MOLD), or non-fluorescent, non-crosslinking adducts such as carboxymethyllysine (CML), carboxymethylcysteine (CMC) and argpyrimidine are the most common ALEs/AGEs formed under protein modification (Figure 13). CML was the first AGE isolated from glycated proteins in vivo and together with pentosidine and glucosepan was recognized as one of the most important biomarkers of glycation in living organisms (Ahmed et al., 1986; Jadoul et al., 1999; Miyata et al., 1999; Tessier, 2010). Carboxymethylphosphatidylethanolamine (CMPE) and carboxymethylguanosine (CMG) represent the ALEs/AGEs derived from GO and MGO interation with nucleic acids and phospholipids, respectively (Figure 13).

In general, ALEs and AGEs are poorly degraded complexes, accumulation of which increases with ageing. The above mentioned ALEs/AGEs were detected in a variety of human tissues and serve as biomarkers of aging and age-related disorders (Tessier, 2010). It should be noted that ALEs/AGEs may continue covalent interations with biomolecules giving more complex cross-links. In addition, ALEs and AGEs are efficient sourses of RCS and ROS in vivo (Yim et al., 2001; Takamiya et al., 2003; Thornalley, 2005; Shumaev et al., 2009; Peng et al., 2011). Thus, increase in the concentration of RCS, ALEs and AGEs may result in carbonyl/oxidative stress. 

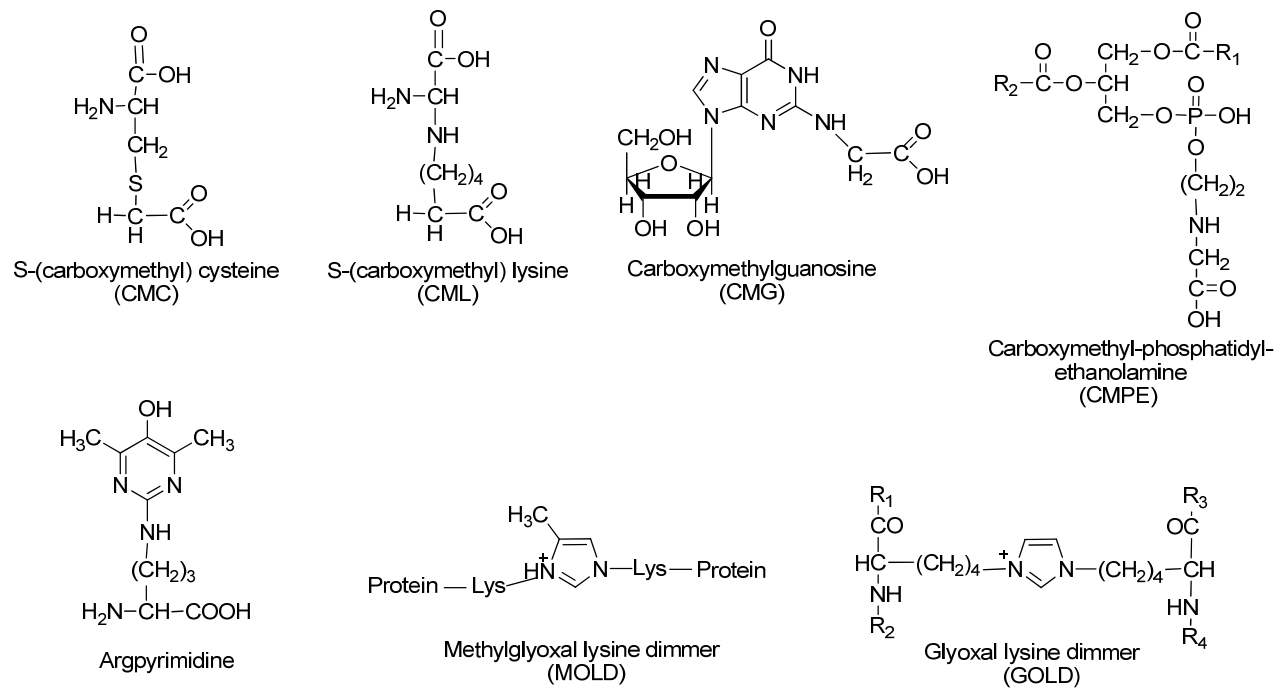

Fig. 13. The structures of the most common advanced end products derived from both glycation and lipoxidation.

\section{Steady-state concentration of carbonyl compounds in vivo and carbonyl stress}

Almost all known RS, in particular ROS and RCS, are continuously produced and eliminated in variuos groups of organisms: bacteria, fungi, plants, and animals (Ponces Freire et al., 2003; Mironova et al., 2005; Yamauchi et al., 2008; Lushchak, 2011b). Since RS are unstable and readily enter many reactions, their concentration is a dynamic parameter and defined as "steady-state". Under normal physiological conditions, the steady-state concentration of RS is maintained at certain range and fluctuates similarly to other parameters in the organism according to homeostasis theory. However, under some circumstances, the parameter may leave this range due to either increase in production or decrease in efficiency of catabolic system. The increase in the steady-state level of ROS or RCS may result in so-called "oxidative stress" or "carbonyl stress", respectively. One of the first definitions of "oxidative stress" as "an imbalance between oxidants and antioxidants in favour of the oxidants, potentially leading to damage" was proposed by Helmut Sies (Sies, 1985). Recently, "oxidative stress" was defined as "an acute or chronic increase in steadystate level of ROS, disturbing cellular metabolism and leading to damage of cellular constituents" (Lushchak, 2011a; b).

The concept of "carbonyl stress" was introduced for the first time by Miyata and colleagues (Miyata et al., 1999). They defined "carbonyl stress" as situation "resulting from either increased oxidation of carbohydrates and lipids (oxidative stress) or inadequate detoxification or inactivation of reactive carbonyl compounds derived from both carbohydrates and lipids by oxidative and nonoxidative chemistry". By analougy with the modern concept of oxidative stress, it can be proposed that "carbonyl stress" is an acute or chronic increase in steady-state level of RCS, ALEs and AGEs disturbing cellular metabolism and leading to damage of cellular constituents. 
In some cases, the steady-state ROS/RCS concentration does not return to initial level, but stabilizes at new one called "quasi-stationary level" (Figure 14). This can be found in certain pathologies, for example diabetes mellitus, atherosclerosis, cardiovascular and neurodegenerative diseases.

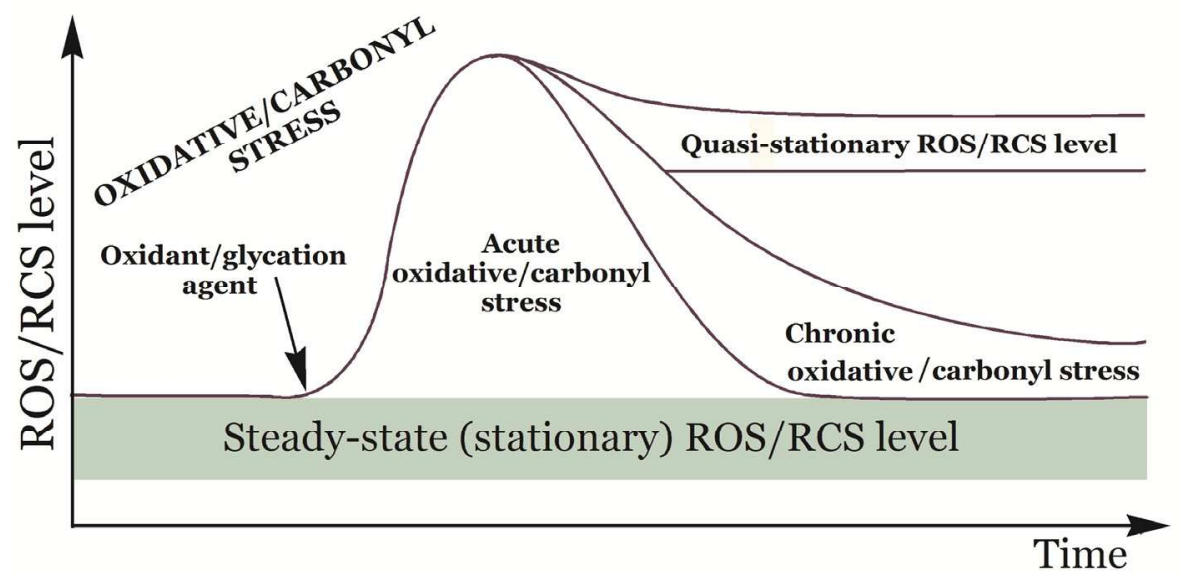

Fig. 14. The dynamics of glycoxidation/lipoxidation-induced perturbations of level of reactive oxygen and carbonyl species in living organisms (modified from (Lushchak, 2011b)).

An obvious question arises: what are the steady-state concentrations of RCS in the cell? Numerous studies demonstrate evaluation of RCS levels in biological systems. For example, it has been reported that overall concentration of LPO end products in plasma of healthy individuals is below $1 \mu \mathrm{M}$ (Niki, 2009). At the same time, NHE has been found in biomembranes at the concentrations from 5 to $10 \mathrm{mM}$ at oxidative insults (Esterbauer et al., 1991). The concentration of fructosamine in blood plasma of healthy individuals has been found about $140 \mu \mathrm{M}$ (Kato et al., 1989). Physiological steady-state concentrations of MGO ranged from 120 to $650 \mathrm{nM}$ (Kalapos, 2008a; Talukdar et al., 2009). Since there are no standard methods to evaluate the steady-state levels of RCS, different techniques applying in various laboratories yield different results. It should be noted that sometimes the increase in RCS levels at certain pathologies reported in one study is significantly lower than the normal levels demonstrated in the other. In addition, there are some objective complications in the evaluation of RCS steady-state level: (i) a vast variety of RCS generated by different mechanisms, leading to difficulties in the identification and quantification of all of them; (ii) simultaneous production, degradation and excretion of RCS; (iii) the influence of different factors (intensity of metabolism, oxygen concentration, temperature, etc.) on the rate of the above processes; and (iv) since the cell is not homogenous structure, in different cellular compartments RCS concentrations may differ to large extent.

Therefore, if we operate with some values reflecting RCS concentrations in biological material, one should be kept in mind that they are only approximate values. To know the levels of RCS in biological fluids and tissues is important to evaluate the extensity of carbonyl/oxidative stress, due to which even approximate assessment of RCS steady-state concentrations in biological material is much better, than the absence of any idea on their amounts in living organism. 


\section{Lipoxidation and glycoxidation are processes linking carbonyl and oxidative stresses}

Glycation and LPO are closely linked with oxidative stress (Figure 15). Oxidation reactions and ROS have been shown to be involved and frequently accelerate the advanced glycation process (Tessier, 2010). That is why "glycoxidation" term has been introduced (Dyer et a., 1991).

In 1980s, oxidative steps in Maillard reaction pathway were described for the first time (Hayashi and Namiki, 1980; Namiki and Hayashi, 1983). The authors found that the unstable Shiff bases could lead to the formation of reactive a-oxoaldehydes and hydrogen peroxide (Figure 8). Later other ROS were identified as products of Shiff base decomposition (Mullarkey et al., 1990). Wolff pathway (Figure 9), another oxidative pathway, was described several years later (Thornalley et al., 1984; Wolff et al., 1991). It has been suggested that metal-catalyzed autooxidation of reducing carbohydrates could be involved in the formation of AGEs and ROS. Amadori products were also shown to be capable to autoxidation (Figure 7) leading to the formation of reactive dicarbonyl compounds, superoxide anion and hydroxyl radical (Hunt et al., 1988; Mullarkey et al., 1990). Thus, all stages of glycoxidation generate ROS, some of them are common with LPO reactions (Figure 15). Chemical modification of amino groups in biomolecules during LPO is called lipoxidation. Products of lipoxidation were found to increase the concentration of some AGEs (Requena et al., 1996; Miyata et al., 2001). The level of proteins modified during LPO may serve as indicators of oxidative and carbonyl stresses in vivo. An example of a nonenzymatically modified amino acid is CML. Being either AGE or ALE, it is a good marker of both glycoxidation and lipoxidation reactions (Requena et al., 1996).

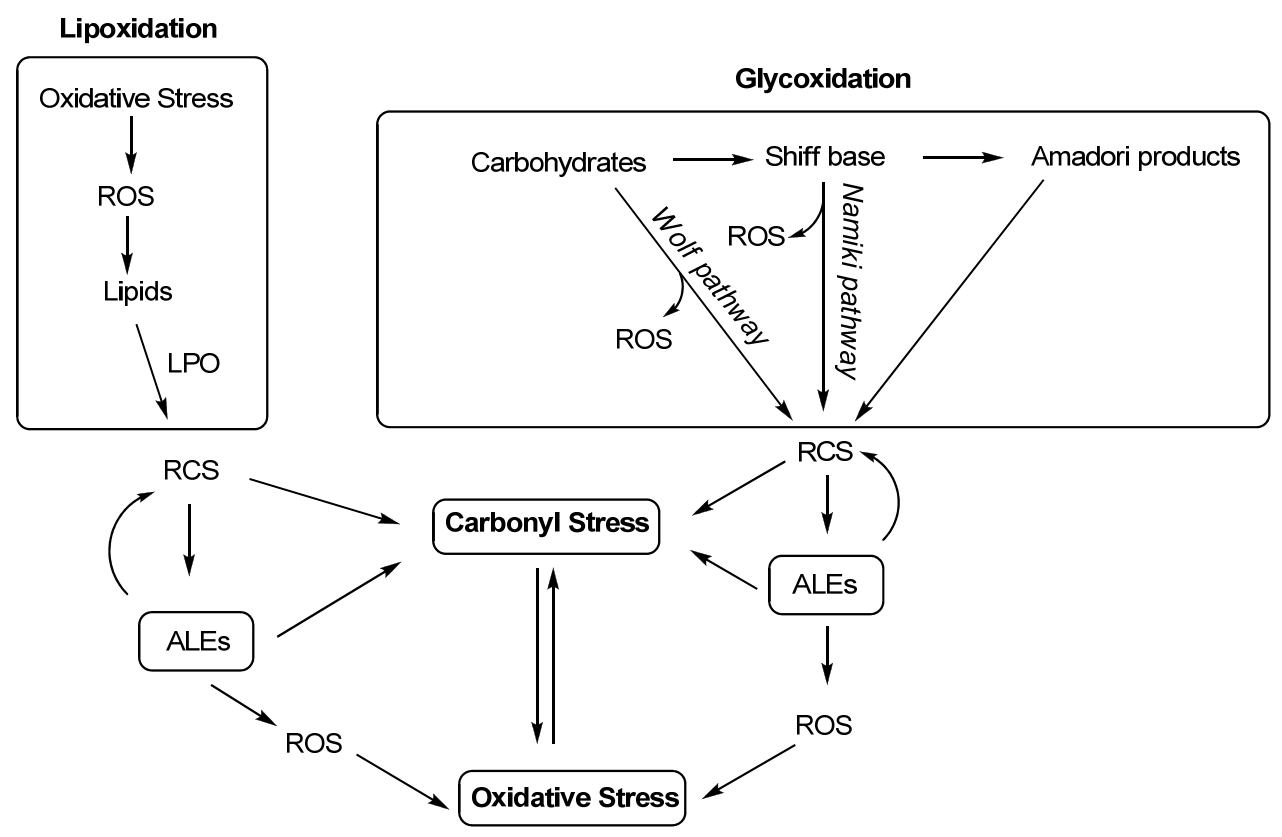

Fig. 15. Relation between lipoxidation, glycoxidation and carbonyl/oxidative stress. 
The existence of a strong relation between carbonyl and oxidative stresses can be proved by ROS formation in the presence of low molecular mass reactive carbonyls. In 1993, MGOinduced ROS production was observed (Kalapos et al., 1993). A dose-dependent effect of MGO on ROS formation, mainly hydrogen peroxide, was detected in cultured rat hepatocytes. Enhanced superoxide anion generation was registered in Jurkat cells incubated with MGO also (Du et al., 2001). It is interesting that the inhibition of superoxide dismutase (SOD) by diethyldithiocarbamate doubled the rate of superoxide formation in the stressed cells.

Glycation is suggested to amplify oxidative stress in several ways. First of all, glycation of antioxidant enzymes can lead to increased ROS level. For instance, $\mathrm{Cu}, \mathrm{Zn}-\mathrm{SOD}$ was found to be highly susceptible to glycation (Arai et al., 1987; Takamiya, et al., 2003). Arai and colleagues (1987) demonstrated that glycation lead to gradual inactivation of the enzyme. The inactivation, in turn, can increase the ROS steady-state level and amplify the oxidative stress. Takamiya with co-authors (2003) showed that the mutated Cu,Zn-SOD was highly susceptible to glucation and fructation. Both glucated and fructated mutant also produced higher levels of hydrogen peroxide than the wild type. The authors suggested that high susceptibility of mutated $\mathrm{Cu}, \mathrm{Zn}$-SOD to glycation could be the origin of the oxidative stress associated with neuronal dysfunction in familial amyotrophic lateral sclerosis (Takamiya, et al., 2003). Low molecular mass reactive carbonyls (e.g. MGO) were found to decrease the level of reduced gluthatione (GSH) in different cells in vivo (Kalapos, 2008a). The situation seems to be more dramatic if one would take into account that GSH is a cofactor for certain antioxidant and antiglycated enzymes, thus an effective cellular protector against both oxidative and carbonyl stresses. Additionally, MGO was found to inhibit several other defensive enzymes (Kalapos, 1994), that makes the cell more succeptible to oxidative/carbonyl stress.

One more additional way to amplify the oxidative stress by glycation is the activation of membrane receptors by AGEs. For instance, AGEs were found to bind to the cell surface receptor (RAGE). This binding, in turn, triggers cellular events through p38 MAP Kinase, NF-kB, P21 Ras and Jak/STAT pathways (Uchida, 2000; Edeas et al., 2010). It is well known that NF-kB is a transcription factor that regulates different cellular functions. In particular, it activates TNF-a production that increases ROS generation. In conclusion, the increase in RCS steady-state concentrations can be also a consequence of oxidative stress. Thus, a vicious cycle can be formed.

\section{Reducing carbohydrates as a factor of carbonyl/oxidative stress}

From the above sections it may be concluded that, beside highly reactive low molecular mass RCS, carbohydrates such as glucose are quite important glycating agents. Despite some RCS demonstrate 20,000-fold higher reactivity than glucose (Turk, 2010), the latter is much more abundant intra- and extracellular glycation agent. Although only $0.001 \%$ of the total glucose in vivo present in relative unstable acyclic isomer form (capable of initiating glycation), it should be kept in mind that some highly reactive RCS are glycolytic intermediates or by-products of glucose metabolism. Thus it is widely believed that glucose is among the most important contributors to the glycation process. That is why potential role of reducing carbohydrates in the Maillard chemistry is extensively studied with different model systems. It was reported that some carbohydrates react with amino groups of biomolecules much faster than glucose (Sakai et al., 2002; Robert et al., 2010). However, since glucose is the most abundant intra- and extracellular monosaccharide in living 
organisms, most studies in the field of glycation are focused on the glucation. Despite fructose having a stronger reducing capacity and is a faster glycating agent than glucose (Sakai et al., 2002; Robert et al., 2010), fructation has attracted only a minor attention. At the same time, fructose is commonly used as an industrial sweetener and excessively consumed in human diets and as a glucose substitute by diabetes mellitus patients (Gaby, 2005; Tappy et al., 2010; Tappy and Lê, 2010). It is well documented that long-term consumption of excessive fructose is causative in the development of metabolic disorders (Levi and Werman, 1998; Johnson et al., 2007; Moheimani et al., 2010; Yang et al., 2011). But the mechanisms underlying fructose-induced metabolic disturbances are under debates. Recently, using baker's yeast as a model system we demonstrated that cells growing on fructose had higher levels of carbonyl groups in proteins, a-dicarbonyl compounds and ROS as compared with yeast cells growing on glucose (Semchyshyn et al., 2011). Possible mechanism for the generation of a-dicarbonyls and ROS by glucation and fructation is presented in Figure 16.

According to the Maillard reaction, the labile Schiff bases are formed as result of interaction between amino groups of biomolecules and carbonyl groups of reducing monosaccharides. The latter rearrange to form Amadori or Heyns products. Both compounds can be transformed to enediol proteins and then to alkoxyl radicals. Alkoxyl radicals readily react with molecular oxygen generating superoxide anion radical and a-dicarbonyl compounds. Then superoxide can be converted to hydrogen peroxide which produces highly reactive hydroxyl radical. In turn, a-dicarbonyl compounds and ROS are the major factors associated with oxidative/carbonyl stress.

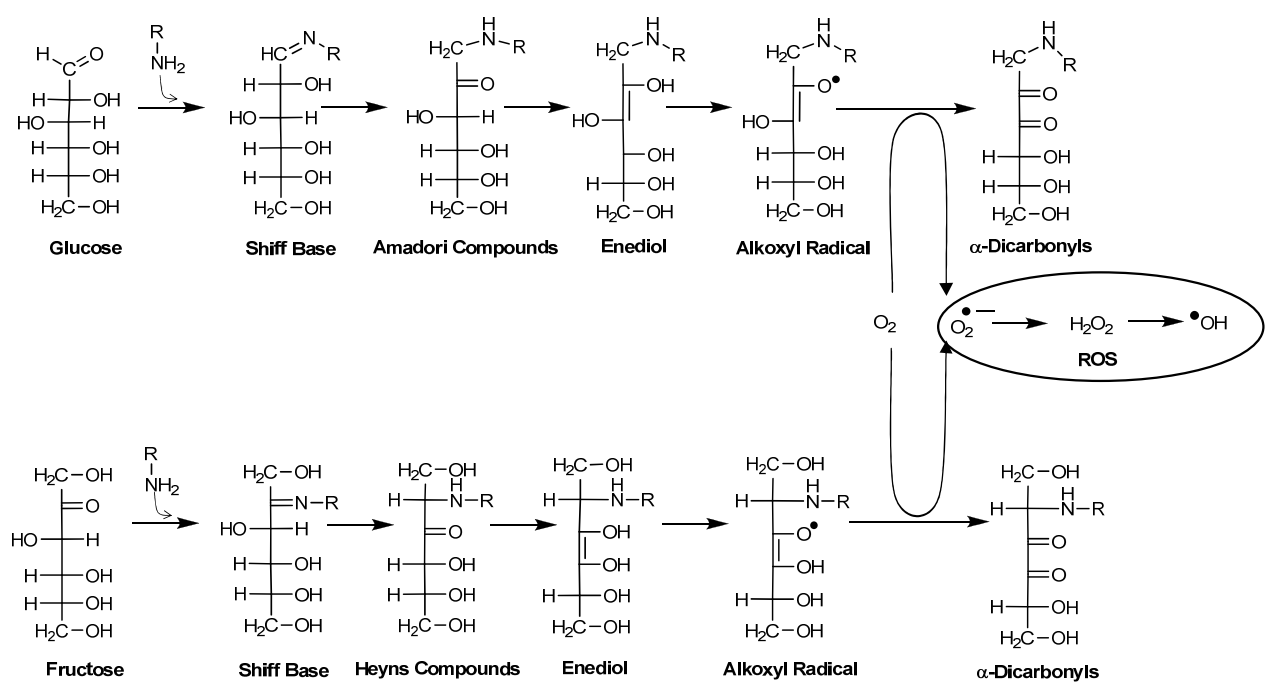

Fig. 16. Formation of a-dicarbonyl compounds and ROS by the glucation and fructation (modified from (Semchyshyn et al., 2011))

In general, our data explain the observation that fructose-supplemented growth as compared with growth on glucose resulted in more pronounced age-related decline in yeast reproductive ability and higher cell mortality (Semchyshyn et al., 2011; Lozinska and 
Semchyshyn, 2011). We suggest that fructose rather than glucose is more extensively involved in glycation and ROS generation in vivo, yeast aging and development of carbonyl/oxidative stress.

\section{Dual biological role of reactive carbonyl and oxygen species}

Generally, RS are better known for their cytotoxic effects. As discussed in the preceding sections, glycation of amino groups of various biomolecules leads to diverse types of modifications. At the molecular level, modifications caused by RCS can: (i) disrupt the structure and function of proteins and enzymes, (ii) lead to formation of nucleic acid adducts, and (iii) damage lipids. Generated during the glycoxidation process ROS cause additional harmful impact. As a consequence of these undesirable effects at the cellular and organismal level, the loss of function and even viability can occur.

However, the persistence of RS in cells indicates their evolutionarily selected production in order to perform some useful role in cellular metabolism. The involvement of RCS and ROS in cell signal transduction and immune response is a prominent demonstration of their beneficial role. Understanding of the role of RS and the oxidation/glycation products in signalling has evolved rapidly during the last decades.

\subsection{Cytotoxic, genotoxic and mutagenic effects}

Proteins can be modified by a large number of reactions involving RCS, ROS as well as lipoxidation and glycoxidation advanced products (Uchida, 2000; Ellis, 2007; Lushchak 2007; Pamplona, 2011). The abovementioned compounds were found to interact directly with proteins causing alterations in physico-chemical properties such as conformation, charge, hydrophobicity, elasticity, solubility, electrophoretic mobility, and many others. Among proteins that can be potentially damaged are enzymes, membrane cytosolic and extracellular transporters, signalling components, transcription and growth factors, microtubules. Modification of proteins is often associated with the appearance of additional carbonyl groups, which leads to: (i) decrease in enzyme activity; (ii) inactivation or modification of regulatory properties; (iii) formation of intra- and intermolecular protein cross-links and adducts; (iv) alteration of protein degradation and formation of toxic aggregates which can inhibit proteasomes; $(v)$ altered folding, processing, and trafficking of proteins; (vi) modification of extracellular matrix properties and cell-matrix interactions; and (vii) stimulation of autoimmune response (Ellis, 2007; Lushchak 2007; Thornalley, 2008; Lesgards et al., 2011; Pamplona, 2011).

Nucleic acids are the most favoured targetes for interaction with RS. It is well known that single stranded nucleic acids are particularly susceptible to modification by RS. The mutagenicity of such RCS as MGO and involvement of ROS in this effect is known for a long time (Kalapos, 2008a). Reactive carbonyl and oxygen species induce mutations frequently detected in oncogenes or tumor suppressor genes from human tumors, and correlate to alterations in cell cycle control and gene expression. Nucleic acid lipoxidative and glycoxidative damages were found in DNA of healthy humans and different animal species at biologically significant levels (Pamplona, 2011). In general, interaction between RS and nucleic acids was suggested to be implicated in carcinogenic, mutagenic and teratogenic actions of RCS and ROS, and products of these interations have powerful 
effects on signal transduction pathways (Ellis, 2007; Kalapos, 2008a; Thornalley, 2008; Niki, 2009; Pamplona, 2011).

Lipid reactions with RCS and ROS can contribute to: (i) modification of mitochondrial membranes disturbing cellular energetics, (ii) $\mathrm{Ca}^{2+}$ release and uncontrolled activation of $\mathrm{Ca}^{2+-}$ dependent pathways due to disruption of endoplasmic reticulum and mitochondrial membranes by RCS and ROS, and (iii) permeabilization of biological membranes and cell lysis (Negre-Salvayre et al., 2008; Pamplona, 2011). As noted above, increase in the levels of lipoxidation and glycoxidation products may lead to propagation of oxidative modifications.

In conclusion, the moleclar modifications caused by RCS, ROS, ALEs and AGEs are nonenzymatic, spontaneous, and random chemical reactions, therefore, the detailed mechanisms of their harmful effects are mostly unknown.

\subsection{Reactive carbonyl and oxygen species are potential aging and age-related pathogenetic factors}

Carbonyl/oxidative stress induces biomolecule dysfunctions and damages in different tissues, which are related to aging and age-related pathologies. In 1950s, Gercshman and colleagues proposed the free radical theory of diseases where suggested ROS involvement in damage of living cells and tissues (Gercshman et al., 1954). This was the background for free radical theory of aging developed by Harman somewhat later (1956). The free radical theory of aging states that ROS continuously damage proteins, lipids, and nucleic acids and thus cause the accumulation of molecular and cellular damages that are responsible for aging and age-related diseases. In 1980s, Monnier and Cerami postulated that the Maillard reaction has a causative role in aging and age-related pathologies (Monnier and Cerami, 1981). This theory called the "glycation hypothesis of aging" was at the origin of the growing interest in the field of the Maillard chemistry in vivo (Tessier, 2010). Nowadays it is obviously that there is a considerable overlap between carbonyl and oxidative stresses in relation to aging and age-related disturbances. As could be seen from the above sections, RCS can be produced as a consequence of oxidative stress, and ROS can be generated due to carbonyl stress.

The formation and accumulation of AGEs and ALEs have been known to progress in a normal aging process, and at an accelerated rate under age-related disorders. A survey of literature reveals the increase in the steady-state concentrations of ROS, RCS, AGEs and ALEs is related to hypertension, kidney and heart diseases, cancer growth and metastasis, obesity, metabolic syndrome, diabetes, degenerative bone disease, etc. (Uchida, 2000; Atanasiu et al., 2006; Ellis, 2007; Lushchak, 2007; Negre-Salvayre et al., 2008; Kalapos, 2008a; Yamagish, 2011; Yang et al., 2011). Chronic hyperglycemia is a major inducer of vascular complications of diabetes, which are responsible for disabilities and high mortality rates in patients with diabetes. Among the various biochemical pathways which are supposed to be involved in vascular complications in diabetes (e.g. heart disease, stroke, blindness and endstage renal failure), the enhanced production of ROS, RCS, AGEs and ALEs and their action are most preferable.

Interestingly, the significant increase in dietary fructose over the past 30 years (Gaby, 2005; Tappy et al., 2010; Tappy and Lê, 2010) has recently been associated with the development 
and progression of various age-related disorders such as obesity, glucose intolerance, vascular complications of diabetes, cardiovascular and neurodegenerative diseases, fatty liver and non-alcoholic steatohepatitis (Levi and Werman, 1998; Johnson et al., 2007; Moheimani et al., 2010; Yamagish, 2011; Yang et al., 2011). However, short-term application of fructose demonstrated better protective action against oxidative stress than glucose (Spasojević et al., 2009a; 2009b). It was suggested that any excess of fructose should be eliminated from normal diets. On the other hand, short-term acute application of fructose has protective effects under pathophysiological conditions related to oxidative stress (Spasojević et al., 2009a; 2009b).

Carbonyl and oxidative stresses have been found to be causative in the activation of cell death pathways such as apoptosis and necrosis (Ellis, 2007; Negre-Salvayre et al., 2008; Uchida, 2010; Lushchak, 2011b; Yamagish, 2011). For instance, HNE alters mitochondrial calcium uptake and cytosolic calcium homoeostasis, which results in necrosis or apoptosis. Low molecular mass reactive carbonyls, MGO and GO, and AGEs are found to be pro-apoptotic through mechanisms involving calcium deregulation, GSH depletion, and activation of stress kinases (Bohlender et al., 2005; Negre-Salvayre et al., 2008; Yamagish, 2011).

\subsection{AGE-Receptors, signal transduction and oxidative stress}

In the middle of the 1980s, it was demonstrated that macrophages could specifically recognize, uptake and degrade AGE-modified proteins in vitro (Vlassara et al., 1985). This observation led to an active search for high affinity AGE receptors on various cells. Now it is well known that the influence of RCS, ROS, ALEs and AGEs on cell is mostly mediated by receptors (Robert 2010; Tessier, 2010). The first discovered cellular surface multiligand receptor capable to bind AGE-modified proteins with high affinity was RAGE (the receptor for AGE) (Schmidt et al., 1992). Extensive search for new AGE receptors resulted in identification of macrophage scavenger receptors (MSR) type A and B1 (CD36), oligosaccharyl transferase-48 termed AGE receptor 1 (AGE-R1), 80K-H phosphoprotein (AGE-R2), and galectin-3 (AGE-R3), but the best studied is the RAGE receptor (Bohlender et al., 2005; Peyroux and Sternberg, 2006). The latter is a 35-kDa protein belonging to the immunoglobulin superfamily. RAGE is a transmembrane receptor consisting of 394 amino acid residues with a single hydrophobic transmembrane domain of 19 amino acids and a COOH-terminal cytosolic tail of 43 amino acids (Bohlender et al., 2005).

In the presence of extracellular AGE, susceptible cells can rapidly upregulate expression of RAGE. Intracellular oxidative stress is among multiple effects caused by interaction of AGEs with RAGE on the membrane of different cells. RAGE activation induces intracellular generation of hydrogen peroxide dependent on NADPH oxidase. The identified signalling cascade involved p21ras, p38, protein kinase C, and MAP kinases (Bohlender et al., 2005; Ucida, 2000). The activation of nuclear factor NF-kB due to AGE and RAGE interaction was also shown to be involved in the regulation of the gene transcription for various factors: endothelin-1, vascular endothelial growth factor (VEGF), transforming growth factor $\beta$ (TGF- $\beta$ ), and tumor necrosis factor a (TNF-a) (Peyroux and Sternberg, 2006). Also, NF-kB controls the expression of almost 100 proinflammatory genes encoding cytokines, adhesion molecules, and ROS/RCS generating enzymes such as NADPH-oxidase, superoxide dismutase, inducible nitric oxide synthase and myeloperoxidase (Bohlender et al., 2005; Anatasiu et al., 2006; Peyroux and Sternberg, 2006; Yamagishi, 2011). 
Therefore, with identification of AGE-recognizing receptors it was realized that glycoxidation plays an important role in age-dependent pathologies and chronic diseases such as diabetes and its complications, inflammation, neurodegeneration, atherosclerosis, amyloidoses, and tumors. It was also found that glycoxidation influenced cell death and proliferation. It cannot be excluded that cross-talk between different receptors activated byAGEs may also be involved in the observed effects. Obviously, the complex RS metabolism is complicated by no less complex molecular mechanisms of their biological effects.

\subsection{Potential beneficial impacts of RCS}

Althought RCS are better known for their harmful effects, their persistence in living organisms indicates that RCS production was evolutionarily selected in order to perform some useful role in cellular metabolism. For instance, phagocytic white blood cells are of central importance in host defense mechanisms implicate RS against invading pathogens. It is demonstrated that, besides ROS, myeloperoxidase generates such RCS as glycolaldehyde, 2-hydroxypropanal, and acrolein (Anderson et al., 1997). Synthesis of RCS by myeloperoxidase required a free hydroxy-amino acid. Since the total concentration of free amino acids in plasma is about $4 \mathrm{mM}$ (Anderson et al., 1997), it seems RCS derived from amino acids are the major products of phagocyte activation in vivo, being important biological weapon fighting infections. Mavric and colleagues (2008) found 3-DG, GO, and MGO in New Zealand Manuka honey possessing very high antibacterial activity. Interestingly, MGO was found to be present at concentrations from 38 to $761 \mathrm{mg} / \mathrm{kg}$, which is up to 100-fold higher compared to conventional honey. Minimum concentrations needed for inhibition of bacterial growth for GO was $6.9 \mathrm{mM}$ (Escherichia coli) or $4.3 \mathrm{mM}$ (Staphylococcus aureus). At the same time, MGO was found to inhibit growth of both bacteria at concentration $1.1 \mathrm{mM}$, and 3-DG showed no inhibition in concentrations up to $60 \mathrm{mM}$. The results clearly demonstrated that the pronounced antibacterial activity of New Zealand Manuka honey directly originated from MGO. Besides its antibacterial activity, MGO demonstrates antiviral effect against New-Castle disease, influenza etc. (Talukdar et al., 2009). Antimalarial and anticancer activities are also among potential beneficial impacts of MGO (Pavlovic-Djuranovic et al., 2006; Talukdar et al., 2009).

\section{Cellular defense against glycation}

The use of a cytotoxic chemical as a signalling molecule, immunological weapon or therapeutic agent obviously has potential risks, so it is no surprise that RCS elimination is tightly regulated in the cell. Similarly to the enzymatic defence against oxidative stress, cell possesses the enzymatic protection system against glycation and carbonyl stress. The antiglycation system includes the enzymes that suppress the formation of RCS and glycoxidative products operating at the respective sites of the process.

Many RCS derived from lipoxidation or glycoxidation can be efficiently metabolized in the enzymatic reactions. They are oxidation, reduction and conjugation, which involve aldehyde and alcohol dehydrogenases, aldo-keto reductases, carbonyl reductases, cytochromes P450, and glutathione-S-transferases (Atanasiu et al., 2006; Ellis, 2007). In these reactions, reactive carbonyls and their advanced products are mainly converted to less toxic compounds, and excreted from cell or organism. 
One of the main pathways known to be involved in the catabolism of a-oxoaldehydes to ahydroxy acids is catalyzed by the glyoxalase system possessed by animals, plants, protoctista, fungi, and bacteria cells (Atanasiu et al., 2006; Ellis, 2007; Xue et al., 2011). The glyoxalase system comprises two cytosolic enzymes: glyoxalase I (Glo I) and glyoxalase II (Glo II), and catalytic amount of GSH. For example, it catalyzes MGO conversion to Dlactate through a specific 2-step pathway (Figure 17). Glyoxalase I catalyzes isomerization of the hemithioacetal, formed spontaneously from a-oxoaldehydes and GSH, into S-2hydroxyacylglutathione derivates. Glyoxalase II catalyzes the conversion of S-2hydroxyacylglutathione derivates into a-hydroxyacids with subsequent regeneration of GSH consumed in the reaction catalyzed by glyoxalase I. The glyoxalase system was discovered in 1913 (Dakin and Dudley, 1913; Neuberg, 1913; Xue et al., 2011). However, for a long period the biological sence of the pathway catalyzed by the system was under debates. In 1980-1990s, Thornalley suggested the fundamental function of glyoxalases in the metabolism of reactive dicarbonyl metabolites to less reactive products (Thornalley, 1990). Nowadays, numeruos experimental data confirm the relation of decrease in the glyoxalase activities to aging and age-related pathologies (Xue et al., 2011).

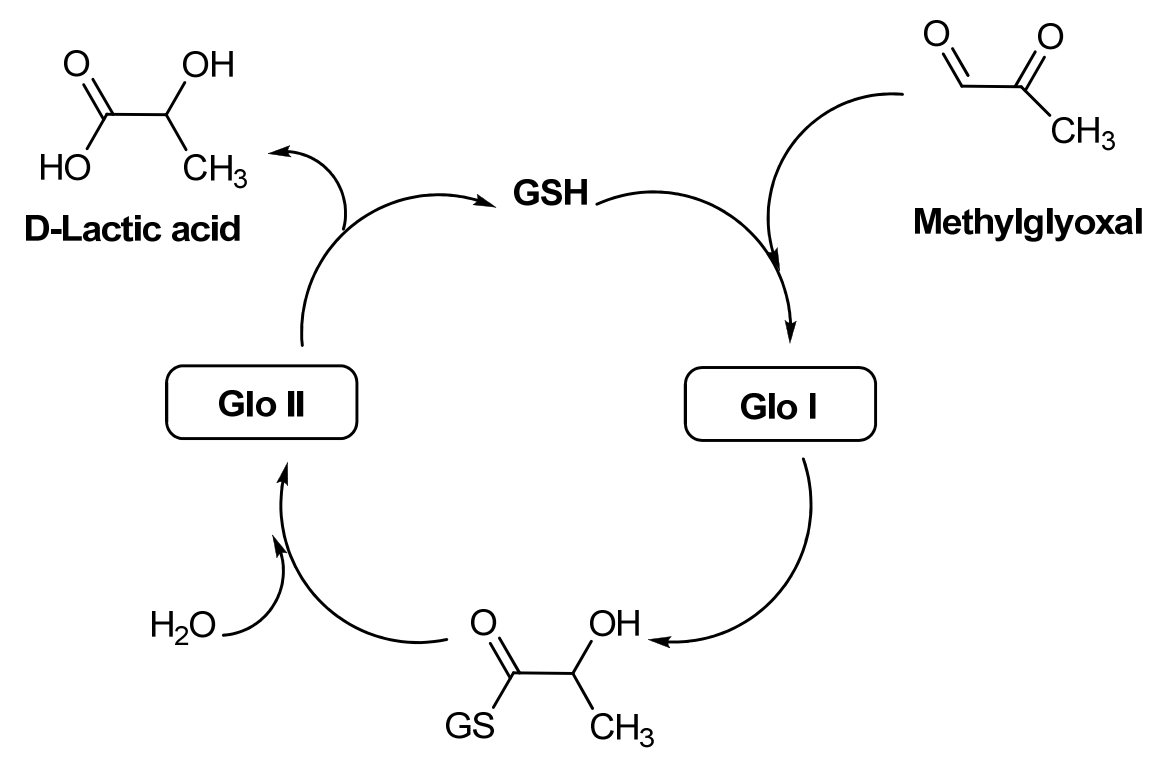

\section{S-D-lactoylglutathione}

Fig. 17. Methylglyoxal degradation by the glyoxalase system.

The antiglycation system also includes highly specific and efficient enzymes recognizing and decomposing Amadori products. Commonly they are called "amadoriases". The latters are divided into two groups, operating via different deglycating mechanisms ( $\mathrm{Wu}$ and Monnier, 2003): fructosylamine oxidases (Figure 18) and fructosylamine kinases (Figure 19). As seen from the figures, a significant action of the amadoriases is connected to the transformation of reactive carbonyls to less reactive products. 


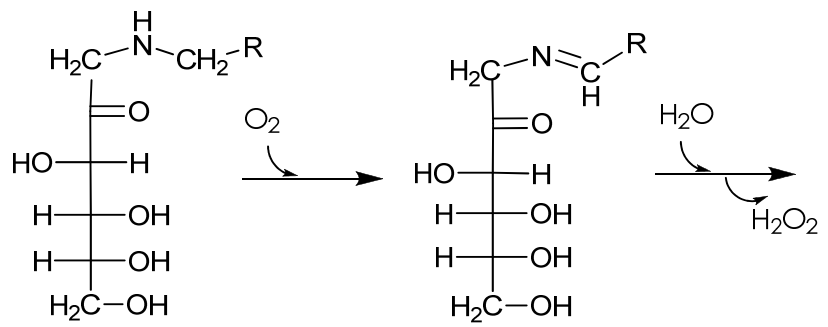

Amadori Compound<smiles>[R]C=O</smiles>

Fructosamine

Fig. 18. Degradation of Amadori compound by fructosylamine oxidase.<smiles>[R]NCC(=O)C(O)C(O)C(O)CO</smiles>

Amadori Compound<smiles>[R]NCC(=O)C(O)C(O)C(O)C(O)COP(=O)(O)O</smiles><smiles>[R]NC[C@H](O)[C@@H](O)[C@@H](O)[C@H](C)[C@H](O)C=O</smiles>

Glucose-6-phosphate

Fig. 19. Degradation of Amadori compound by fructosylamine kinase.

The enzymatic mechanisms described in this section let us conclude that reactive carbonyls, and related carbonyl stress are not only natural attributes of life, but they have also been a determinant factor, which demanded functional adaptations living organisms that, in turn, determined their viability and longevities. Moreover, in the past years glyoxalase as well as amadoriases have been targeted for the development of novel antitumor, antiprotozoal, antifungal and antibacterial agents.

\section{Therapeutic strategies to fight against carbonyl/oxidative stress}

Considering the emerging deleterious role of reactive carbonyls and their advanced products in different human diseases, various potential therapeutic strategies have been developed last years. Different stages of RCS, ALE and AGE formation and AGE-mediated damage are suggested as therapeutic intervention strategies (Peyroux and Sternberg, 2006; Aldini et al., 2007; Peng et al., 2011). Peyroux and Sternberg (2006) classified these strategies as follows: (i) trapping of reactive dicarbonyl species, (ii) AGE cross-link cleavage, (iii) AGE receptor blocking, (iv) AGE receptor signalling blocking, (v) glycemia reduction by antidiabetic therapy, (vi) aldose reductase inhibition; (vii) shunting of trioses-phosphate toward the pentose-phosphate pathway by transketolase activation; (viii) antioxidant therapy by transition metal chelation and free radical scavenging. As a consequence, many compounds that prevent the formation of AGEs or degrade the existing AGEs have been produced in recent years. Among others are amadoriases, aminoguanidine, pyridoxamine, drugs used in the treatment of type 2 diabetes such as metformin and pioglitazone, angiotensin receptor blockers and inhibitors of angiotensin converting enzyme, amino group capping agents such 
as aspirin, compounds that mostly break alpha-dicarbonyl cross-links such as phenacylthiazolium bromide.

Since oxidative stress accompanies and accelerates carbonyl stress, antioxidant compounds appear to be promising agents for the prevention of AGE and ALE formation. The antiglycation activities of medical plant materials and naturally occurring phenolic compounds with antioxidant properties are of particular interest (Peyroux and Sternberg, 2006; Edeas, 2010; Peng et al., 2011).

\section{Concluding remarks and perspectives}

The continuous production and catabolism of RCS result in maintaining of certain steadystate level in living organisms. Being intermediates of certain metabolic pathways, their level to some extent may be regulated. But substantial RCS portion is produced in nonenzymatic chemical processes and, therefore, is difficult to be controlled by living organisms. The same can be said on the elimination of RCS due to concerted activity of enzymatic and non-enzymatic mechanisms. Therefore, the steady-state RCS level is controlled by the cell to large extent, but some room is left out of the cellular control.

High chemical reactivity of RCS determines their biological activity mainly deleterious for living organisms. If at normal physiological state the production and catabolism are well balanced, at certain conditions RCS steady-state level may be transiently increased leading to development of so-called "acute carbonyl stress". Since the cell possesses multilevel defense system, it can combat RCS and return their level into initial steady-state range. The protective potential can be enhanced by up-regulation of defense mechanisms such as glutathione production, specific enzymes like glutathione-S-transferases or glyoxalases. In this case, short-term RCS-induced stress may have no series consequences for living organisms, and even can be beneficial because of increased capability to eliminate RCS. Moreover, it can also increase cell capability to combat other RS like ROS. However, under some circumstances the defense systems of organisms may be overwhelmed and the RCS steady-state level can be maintained increased for a long time. The situation may be called "chronic carbonyl stress". This one can result in the development of different pathological states alone or in combination with other mechanisms leading to diseases and aging. To date, general aspects of RCS homeostasis have been delineated, but a lot of aspects have not been clarified.

Some data shed light on the interplay between the stresses induced by RCS and ROS and in some cases the both may lead to the formation of a vicious cycle. On the other hand, interplay between these stresses, especially under well controlled conditions may be used as preventive approach. For example, the activity of glutathione-S-transferase is up-regulated by both ROS and RCS. It can be used to enhance a potential of RCS defense mechanisms by the induction of mild oxidative stress. Since the molecular details of up-regulation of antioxidant mechanisms is much better studied, the lessons from it can be transferred to RCS field. In some cases, the antioxidant potential can be enhanced ever without induction of oxidative stress and this provides some clues to protect organisms against deleterious RCS effects. Since RCS have been shown to be related to many diseases, the described above aspects can be used to identify appropriate therapeutic targets. 
Although there are many identified RCS, there is no doubt that in future new species will be identified. Especially it is true for big biologically important molecules like proteins and nucleic acids. However, the development of standardized conventional methods for RCS identification would provide better conditions for inter-laboratory comparison of data received. These new techniques are more than welcomed. Due to important RCS role in the development of various pathologies, the reliable measurement methods would provide a progress not only in basic investigations, but also in applied ones.

The role of RCS in regulation of cellular processes is another topic waiting for investigation. In addition to described to date influence on NF-kB, MAP kinases, TNF one can expect at least their modulatory effects on diverse regulatory cascades via direct interaction with components of regulatory cascades, or indirect via change in level or properties of connected partners.

Currently, we are only at the beginning of therapeutic targeting disorders connected with deleterious RCS effects. Probably, glutathione and glutathione-dependent enzymes along with other components of antioxidant system are the best studied targets from medical point of view. Much less is known on the use of specific compounds which may help to combat RCS-induced or supported pathologies. Although the detail molecular mechanisms are not known, dipeptide carnosine ( $\beta$-alanyl-L-histidine) and related compounds was proposed to be used as potential beneficial agents to cure diseases related with the stress induced by reactive carbonyls. Since carnosine is found in animals, it is used as an argument for carnivorous against vegetarian diets. There is no doubt that new discoveries in RCS homeostasis will open new avenues for modulation of processes caused by them.

\section{Acknowledgment}

We would like to express our sincere gratitude and appreciation to Professor M. Carini and Professor M. P. Kalapos for sending a valuable information. Our special thank to PhD students Liudmyla Lozinska and Olexandr Lozinsky for excellent technical assistance in the illustration preparation.

\section{Abbreviations}

3DG, 3-deoxyglucosone; AGEs, advanced glycation end products; ALEs, advanced lipoxidation end products; $\mathrm{CMC}$, carboxymethylcysteine; $\mathrm{CMG}$, carboxymethylguanosine; CML, carboxymethyllysine; CMPE, carboxymethyl-phosphatidylethanolamine; Glo I, glyoxalase I; Glo II, glyoxalase II; GO, glyoxal; GOLD, glyoxal-lysine dimer; GSH, reduced glutathione; HNE, 4-hydroxy-trans-2-nonenal; LPO, lipid peroxidation; MDA, malondialdehyde; MGO, methylglyoxal; MOLD, methylglyoxal-lysine dimer; ONE, 4-oxotrans-2-nonenal; PUFAs, polyunsaturated fatty acids; RAGE, the receptor for AGE; RCS, reactive carbonyl species; ROS, reactive oxygen species; RS, reactive species; SOD, superoxide dismutase;TNF- $\alpha$, tumor necrosis factor $\alpha$; TGF- $\beta$, transforming growth factor $\beta$; VEGF, vascular endothelial growth factor.

\section{References}

Ahmed, MU., Thorpe, SR. \& Baynes, JW. (1986). Identification of $\mathrm{N}$ epsiloncarboxymethyllysine as a degradation product of fructoselysine in glycated protein, J. Biol. Chem. 261(11):4889-4894. 
Aldini, G., Dalle-Donne, I., Facino, RM., Milzani, A. \& Carini, M. (2007). Intervention strategies to inhibit protein carbonylation by lipoxidation-derived reactive carbonyls, Med. Res. Rev. 27(6):817-868.

Anderson, MM., Hazen, SL., Hsu, FF. \& Heinecke, JW. (1997). Human neutrophils employ the myeloperoxidase-hydrogen peroxide-chloride system to convert hydroxyamino acids into glycolaldehyde, 2-hydroxypropanal, and acrolein. A mechanism for the generation of highly reactive alpha-hydroxy and alpha, beta-unsaturated aldehydes by phagocytes at sites of inflammation, J. Clin. Invest. 99(3):424-432.

Atanasiu, V., Stoian, I., Manolescu, B. \& Lupescu, O. (2006). The glyoxalase system - a link between carbonilic stress and human therapy, Rev. Roum. Chim. 51(9):861-869.

Birlouez-Aragon, I., Morales, F., Fogliano, V. \& Pain, JP. (2010). The health and technological implications of a better control of neoformed contaminants by the food industry, Pathol. Biol. (Paris). 58(3):232-238.

Bohlender, JM., Franke, S., Stein, G. \& Wolf, G. (2005). Advanced glycation end products and the kidney, Am. J. Physiol. Renal. Physiol. 289: F645 - F659.

Chaplen, FWR., Fahl, WE. \& Cameron DC. (1996). Detection of methylglyoxal as a degradation product of DNA and nucleic acid components treated with strong acid, Anal. Biochem. 236:262-269.

Chung, SS., Ho, EC., Lam, KS. \& Chung SK. (2003). Contribution of polyol pathway to diabetes-induced oxidative stress, J. Am. Soc. Nephrol.. 14:S233-236.

Colombo, G., Aldini, G., Orioli, M., Giustarini, D., Gornati, R., Rossi, R., Colombo, R., Carini, M., Milzani, A. \& Dalle-Donne I. (2010). Water-soluble $\alpha, \beta$-unsaturated aldehydes of cigarette smoke induce carbonylation of human serum albumin, Antioxid. Redox Signal. 12(3):349-364.

Dakin, HD., Dudley, HW. (1913). An enzyme concerned with the formation of hydroxyl acids from ketonic aldehydes, J. Biol. Chem. 14:155-157.

Demple, B. (1991). Regulation of bacterial oxidative stress genes, Annu. Rev. Genet. 25:315-337.

Dini, L. (2010). Phagocytosis of dying cells: influence of smoking and static magnetic fields, Apoptosis. 15(9):1147-1164.

Du, J., Suzuki, H., Nagase, F., Akhand, AA., Ma, XY., Yokoyama, T., Miyata, T. \& Nakashima, I. (2001). Superoxide-mediated early oxidation and activation of ASK1 are important for initiating methylglyoxal-induced apoptosis process, Free Rad. Biol. Med. 31:469-478.

Dyer, DG., Blackledge, JA., Katz, BM., Hull, CJ., Adkisson, HD., Thorpe, SR., Lyons, TJ. \& Baynes, JW. (1991). The Maillard reaction in vivo, Z. Ernahrungswiss. 30(1):29-45.

Edeas, M., Attaf, D., Mailfert, A.-S., Nasu, M. \& Joubet, R. (2010). Maillard Reaction, mitochondria and oxidative stress: Potential role of antioxidants, Pathol. Biol. (Paris). 58(3):220-225.

Ellis, EM. (2007). Reactive carbonyls and oxidative stress: potential for therapeutic intervention, Pharmacol. Ther. 115(1):13-24.

Esterbauer, H., Schaur, RJ. \& Zollner, H. (1991). Chemistry and biochemistry of 4hydroxynonenal, malondialdehyde and related aldehydes, Free Radical .Biol. Med. 11:81-128.

Esterbauer, H., Schaur, RJ. \& Zollner, H. (1991). Chemistry and biochemistry of 4hydroxynonenal, malondialdehyde and related aldehydes, Free Radic. Biol. Med. 11:81-128. 
Finot, PA. (1982). Nonenzymatic browning products: physiologic effects and metabolic transit in relation to chemical structure. Diabetes. 31(3):22-28.

Gaby, AR. (2005). Adverse effects of dietary fructose, Altern. Med. Rev. 10(4):294-306.

Gerschman, R., Gilbert, DL., Nye, SW., Dwyer, P. \& Fenn, WO. (1954). Oxygen poisoning and x-irradiation: a mechanism in common, Science. 119(3097):623-626.

Halliwell, B., Gutteridge, J.M.C. (1989). Free Radicals in Biology and Medicine. Clarendon Press, Oxford.

Harman, D. (1956). Aging: a theory based on free radical and radiation chemistry, J. Gerontol. 11(3):298-300.

Hayashi, T. \& Namiki, M. (1980). Formation of two-carbon sugar fragments at an early stage of the browning reaction of sugar and amine, Agric.Biol.Chem. 44: 2575-2580.

Hodge, JE. (1953). Chemistry of browning reactions in model systems, J. Agric. Food Chem. 1:928-943.

Hunt, JV., Dean, RT. \& Wolff, SP. (1988). Hydroxyl radical production and autoxidative glycosylation, Biochem. J. 256: 205-212.

Jadoul, M., Ueda, Y., Yasuda, Y., Saito, A., Robert, A., Ishida, N., Kurokawa, K., Van Ypersele De Strihou, C. \& Miyata, T. (1999). Influence of hemodialysis membrane type on pentosidine plasma level, a marker of "carbonyl stress", Kidney Int. 55(6):2487-2492.

Johnson, RJ., Segal, MS., Sautin, Y.,Nakagawa, T., Feig, DI.,Kang, DH., Gersch, MS.,Benner, S. \& Sanchez-Lozada, LG. (2007). Potential role of sugar (fructose) in the epidemic of hypertension, obesity and the metabolic syndrome, diabetes, kidney disease, and cardiovascular disease, Am. J. Clin. Nutr. 86:899-906.

Kalapos, MP. (2008a). The tandem of free radicals and methylglyoxal, Chem. Biol. Interact. 171(3):251-271.

Kalapos, MP. (2008b). Methylglyoxal and glucose metabolism: a historical perspective and future avenues for research, Drug. Metabol. Drug. Interact. 23(1-2):69-91.

Kalapos, MP., Littauer, A. \& de Groot, H. (1993). Has reactive oxygen a role in methylglyoxal toxicity? A study on cultured rat hepatocytes, Arc. Toxicol. 67:369-372.

Kato, M., Nakayama, H., Makita, Z., Aoki, S., Kuroda, Y., Yanagisawa, K. \& Nakagawa, S. (1989). Radioimmunoassay for non-enzymatically glycated serum proteins, Horm. Metab. Res. 21:245-248.

Lankin, VZ., Tikhaze, AK., Kapelko, VI., Shepelkova, GS., Shumaev, KB., Panasenko, OM., Konovalova, GG. \& Belenkov, YN. (2007). Mechanisms of oxidative modification of low density lipoproteins under conditions of oxidative and carbonyl stress, Biochemistry (Mosc). 72(10):1081-1090.

Lesgards, J.-F., Gauthier, C., Iovanna, J., Vidal, N., Dolla, A. \& Stocker, P. (2011). Effect of reactive oxygen and carbonyl species on crucial cellular antioxidant enzymes, Chem. Biol. Interact. 190:28-34.

Levi, B. \& Werman, MJ. (1998). Long-term fructose consumption accelerates glycation and several age-related variables in male rats, J. Nutr. 128(9): 1442-1449.

Liu, X.-Y., Zhu, M.-X. \& Xie, J.-P. (2010). Mutagenicity of acrolein and acrolein-induced DNA adducts, Toxicol. Mech. Meth. 20(1):36-44.

Lozinska LM., Semchyshyn HM. (2011). Fructose as a factor of carbonyl/oxidative stress development and accelerated aging in the yeast Saccharomyces cerevisiae, Ukrainian Biochem. J. 83(4):62-71. 
Lushchak, VI. (2007). Free radical oxidation of proteins and its relationship with functional state of organisms, Biochemistry (Mosc). 72(8):809-827.

Lushchak, VI. (2011a). Environmentally induced oxidative stress in aquatic animals, Aquat. Toxicol. 101(1):13-30.

Lushchak, VI. (2011b). Adaptive response to oxidative stress: Bacteria, fungi, plants and animals, Comp. Biochem. Physiol. C Toxicol. Pharmacol. 153(2):175-190.

Lushchak, VI., Semchyshyn, HM., Lushchak OV. (2011c). "Classic" methods for measuring of oxidative damage: TBARS, xylenol orange, and protein carbonyls, in textbook: Oxidative Stress in Aquatic Ecosystems, editors D. Abele, T. Zenteno-Savin, J. Vazquez-Medina, Blackwell Publishing Ltd., 420-431.

Lyles, GA. \& Chalmers, J. (1992) The metabolism of aminoacetone to methylglyoxal by semicarbazide-sensitive amine oxidase in human umbilical artery, Biochem. Pharmacol. 43:1409-1414.

Maillard, LC. (1912). Action des acides aminés sur les sucres: formation des mélanoïdines par voie méthodique. C. R. Acad. Sci. 154:66-68.

Mavric, E., Wittmann, S., Barth, G. \& Henle, T. (2008). Identification and quantification of methylglyoxal as the dominant antibacterial constituent of Manuka (Leptospermum scoparium) honeys from New Zealand, Mol. Nutr. Food Res. 52(4):483-489.

Mironova, R., Niwa, T., Handzhiyski, Y., Sredovska, A. \& Ivanov, I. (2005). Evidence for non-enzymatic glycosylation of Escherichia coli chromosomal DNA, Mol. Microbiol. 55(6):1801-1811.

Miyata ,T., Saito, A., Kurokawa, K. \& van Ypersele de Strihou C. (2001). Advanced glycation and lipoxidation end products: reactive carbonyl compounds-related uraemic toxicity, Nephrol. Dial. Transplant. 16(4):8-11.

Miyata, T., van Ypersele de Strihou, C., Kurokawa, K. \& Baynes, JW. (1999). Alterations in nonenzymatic biochemistry in uremia: origin and significance of "carbonyl stress" in long-term uremic complications, Kidney Int. 55(2):389-399.

Moheimani, F., Morgan, PE., van Reyk, DM. \& Davies, MJ. (2010). Deleterious effects of reactive aldehydes and glycated proteins on macrophage proteasomal function: possible links between diabetes and atherosclerosis, Biochim. Biophys. Acta. 1802(6):561-571.

Monnier, VM. \& Cerami, A. (1981). Nonenzymatic browning in vivo: possible process for aging of long-lived proteins, Science. 211:491 - 493.

Mullarkey, CJ., Edelstein, D. \& Brownlee, M. (1990). Free radical generation by early glycation products: a mechanism for accelerated atherogenesis in diabetes, Biochem. Biophys. Res. Commun. 173(3):932-939.

Namiki, M. \& Hayashi, T. (1983). A new mechanism of the Maillard reaction involving sugar fragmentation and free radical formation. In: Waller, GR. \& Feather, MS. (Eds). The Maillard reaction in foods and nutrition. ACS Symposium, Series 215. Washington DC: American Chemical Society.

Negre-Salvayre, A., Coatrieux, C., Ingueneau, C. \& Salvayre, R. (2008). Advanced lipid peroxidation end products in oxidative damage to proteins. Potential role in diseases and therapeutic prospects for the inhibitors. Br. J. Pharmacol. 153(1):6-20. 
Negre-Salvayre, A., Coatrieux, C., Ingueneau, C. \& Salvayre, R. (2008). Advanced lipid peroxidation end products in oxidative damage to proteins. Potential role in diseases and therapeutic prospects for the inhibitors, Br. J. Pharmacol. 153(1):6-20.

Neuberg, C. (1913). The destruction of lactic aldehyde and methylglyoxal by animal organs, Biochem. Z. 49:502-506.

Niki, E. (2000). Free radicals in the 1900's: from in vitro to in vivo. Free Radic. Res. 33(6):693-704.

Niki, E. (2009). Lipid peroxidation: Physiological levels and dual biological effects. Free Radic. Biol. Med. 47:469-484.

Niwa, T. (1999). 3-Deoxyglucosone: metabolism, analysis, biological activity, and clinical implication, J. Chromatogr. B. Biomed. Sci. Appl. 731:23-36.

Pamplona, R. (2008). Membrane phospholipids, lipoxidative damage and molecular integrity: A causal role in aging and longevity. Biochim. Biophys. Acta. 1777:1249-1262.

Pamplona, R. (2011). Advanced lipoxidation end-products, Chem. Biol. Interact. 192(1-2):14-20.

Pavlovic-Djuranovic, S., Kun, JF., Schultz, JE. \& Beitz, E. (2006). Dihydroxyacetone and methylglyoxal as permeants of the Plasmodium aquaglyceroporin inhibit parasite proliferation, Biochim. Biophys. Acta. 1758(8):1012-1017.

Peng, X., Ma, J., Chen, F. \& Wang, M. (2011). Naturally occurring inhibitors against the formation of advanced glycation end-products, Food Funct. 2(6):289-301.

Peyroux, J. \& Sternberg, M. (2006). Advanced glycation endproducts (AGEs): Pharmacological inhibition in diabetes, Pathol. Biol. (Paris). 54(7):405-419.

Phillips, SA. \& Thornalley, PJ. (1993). The formation of methylglyoxal from triose phosphates. Investigation using a specific assay for methylglyoxal, Eur. J. Biochem. 212(1):101-105.

Pompliano, D.L, Peyman, A. \& Knowles, JR. (1990). Stabilization of a reaction intermediate as a catalytic device: definition of the functional role of the flexible loop in triosephosphate isomerase, Biochemistry. 29(13):3186-3194.

Ponces Freire, A., Ferreira, A., Gomes, R. \& Cordeiro, C. (2003). Anti-glycation defences in yeast, Biochem. Soc. Trans. 31(6):1409-1412.

Rahbar, S. (1968). Hemoglobin $\mathrm{H}$ disease in two Iranian families, Clin. Chim. Acta., 20(30):381-385.

Rahbar, S., Blumenfeld, O. \& Ranney, HM. (1969). Studies of an unusual hemoglobin in patients with diabetes mellitus, Biochem. Biophys. Res. Commun. 36(5):838-843.

Reihl, O., Rothenbacher, TM., Lederer, MO. \& Schwack, W. (2004). Carbohydrate carbonyl mobility--the key process in the formation of alpha-dicarbonyl intermediates, Carbohydr. Res. 339(9):1609-1618.

Requena, JR., Fu, MX., Ahmed, MU., Jenkins, AJ., Lyons, TJ. \& Thorpe, SR. (1996). Lipoxidation products as biomarkers of oxidative damage to proteins during lipid peroxidation reactions, Nephrol. Dial. Transplant. 11(5):48-53.

Richard, JP. (1993). Mechanism for the formation of methylglyoxal from triosephosphates, Biochem. Soc. Trans. 21(2):549-553.

Robert, L., Labat-Robert, J. \& Robert, AM. (2010). The Maillard reaction. From nutritional problems to preventive medicine, Pathol. Biol. (Paris). 58(3):200-206.

Robert, L., Robert, A.-M. \& Labat-Robert, J. (2011). The Maillard reaction - Illicite (bio)chemistry in tissues and food, Pathol. Biol. (Paris). 59(6):321-328.

Sakai, M., Oimomi, M. \& Kasuga, M. (2002). Experimental studies on the role of fructose in the development of diabetic complications, Kobe J. Med. Sci. 48(5-6):125-136. 
Schmidt, AM., Vianna, M., Gerlach, M., Brett, J., Ryan ,J., Kao, J., Esposito, C., Hegarty, H., Hurley, W., Clauss, M., Feng, W., Pan, YCE., Tsang, TC. \& Stern, D. (1992). Isolation and characterization of two binding proteins for advanced glycosylation end products from bovine lung which are present on the endothelial cell surface, $J$. Biol. Chem. 267(21):14987-1497.

Semchyshyn, HM., Lozinska, LM., Miedzobrodzki, J., Lushchak, VI. (2011). Fructose and glucose differentially affect aging and carbonyl/oxidative stress parameters in Saccharomyces cerevisiae cells, Carbohydr. Res. 346(7):933-938.

Seo, Y.-K. \& Baek, S.-O. (2011). Characterization of carbonyl compounds in the ambient air of an industrial city in Korea, Sensors. 11(1):949-963.

Shao, B., Fu, X., McDonald, TO., Green, PS., Uchida, K., O'Brien, KD., Oram, JF. \& Heinecke, JW. (2005). Acrolein impairs ATP binding cassette transporter A1-dependent cholesterol export from cells through site-specific modification of apolipoprotein AI, J. Biol. Chem. 280(43):36386-36396.

Shumaev, KB., Gubkina, SA., Kumskova, EM., Shepelkova, GS., Ruuge, EK. \& Lankin VZ. (2009). Superoxide formation as a result of interaction of L-lysine with dicarbonyl compounds and its possible mechanism, Biochemistry (Mosc). 74(4):461-466.

Sies, H. (1985). Oxidative stress: introductory remarks. In Sies, H. (Ed.). Oxidative Stress. London: Academic Press. pp. 1-8.

Sies, H. (1986). Biochemistry of oxidative stress. Angewaudte Chemie, International Edition in English 25:1058-1071.

Sies, H. (1991). Oxidative stress: introduction. In Oxidative Stress: Oxidants and Antioxidants. Sies, H. (Ed.). pp. xv-xxii. Academic Press, London.

Spasojević, I., Bajić, A., Jovanović, K., Spasić, M. \& Andjus, P. (2009b). Protective role of fructose in the metabolism of astroglial C6 cells exposed to hydrogen peroxide, Carbohydr. Res. 344(13):1676-1681.

Spasojević, I., Mojović, M., Blagojević, D., Spasić, SD., Jones, DR., Nikolić-Kokić, A. \& Spasić, MB. (2009a). Relevance of the capacity of phosphorylated fructose to scavenge the hydroxyl radical, Carbohydr. Res. 344(1):80-84.

Takamiya, R., Takahashi, M., Myint, T., Park, YS., Miyazawa, N., Endo, T., Fujiwara, N., Sakiyama, H., Misonou, Y., Miyamoto, Y., Fujii, J. \& Taniguchi, N. (2003). Glycation proceeds faster in mutated $\mathrm{Cu}, \mathrm{Zn}$-superoxide dismutases related to familial amyotrophic lateral sclerosis, FASEB J. 17(8):938-940.

Talukdar, D., Chaudhuri, BS., Ray, M. \& Ray, S. (2009). Critical evaluation of toxic versus beneficial effects of methylglyoxal, Biochemistry (Mosc). 74(10):1059-1069.

Tappy, L. \& Lê, KA. (2010). Metabolic effects of fructose and the worldwide increase in obesity, Physiol. Rev. 90(1):23-46.

Tappy, L., Lê, KA., Tran, C. \& Paquot, N. (2010). Fructose and metabolic diseases: new findings, new questions, Nutrition. 26(11-12):1044-1049.

Tessier, FJ. (2010). The Maillard reaction in the human body. The main discoveries and factors that affect glycation, Pathol. Biol. (Paris). 58(3):214-219.

Tessier, FJ., Monnier, VM., Sayre, LM. \& Kornfield, JA. (2003). Triosidines: novel Maillard reaction products and cross-links from the reaction of triose sugars with lysine and arginine residues, Biochem. J. 369(3):705-719.

Thornalley PJ. (2005). Dicarbonyl intermediates in the Maillard reaction, Ann. N Y Acad. Sci. 1043:111-117. 
Thornalley, PJ. (1990). The glyoxalase system: new developments towards functional characterization of a metabolic pathway fundamental to biological life, Biochem. J. 269(1):1-11.

Thornalley, PJ. (2008). Protein and nucleotide damage by glyoxal and methylglyoxal in physiological systems--role in ageing and disease, Drug Metabol. Drug Interact. 23(12):125-150.

Thornalley, PJ., Wolff, SP., Crabbe, J. \& Stern, A. (1984). The autoxidation of glyceraldehyde and other simple monosaccharides under physiological conditions catalysed by buffer ions, Biochim. Biophys. Acta. 797:276-287.

Trotter, EW., Collinson, E J. Dawes, IW. \& Grant CM. (2006). Old yellow enzymes Protept against acrolein toxicity in the yeast Saccharomyces cerevisiae, Appl. Environ. Microbiol. 72(7):4885-4892.

Turk, Z. (2010). Glycotoxines, carbonyl stress and relevance to diabetes and its complications, Physiol Res. 59(2):147-156.

Uchida, K. (2000). Role of reactive aldehyde in cardiovascular diseases, Free Radic. Biol. Med. 28(12):1685-1696.

Uchida, K., Sakai, K., Itakura, K., Osawa, T. \& Toyokuni, S. (1997). Protein modification by lipid peroxidation products: formation of malondialdehyde-derivedNe-(2Propenal)lysine in proteins, Arch. Biochem. Biophys.346(1):45-52.

Uribarri, J. \& Tuttle, KR. (2006). Advanced glycation end products and nephrotoxicity of high-protein diets, Clin. J. Am. Soc. Nephrol. 1(6):1293-1299.

Uribarri, J., Cai, W., Peppa, M., Goodman, S., Ferrucci, L., Striker, G. \& Vlassara H. (2007). Circulating glycotoxins and dietary advanced glycation endproducts: two links to inflammatory response, oxidative stress, and aging. J. Gerontol. A. Biol. Sci. Med. Sci. 62(4):427-433.

Uribarri, J., Woodruff, S., Goodman, S., Cai, W., Chen, X., Pyzik, R., Yong, A., Striker, GE. \& Vlassara H. (2010). Advanced glycation end products in foods and a practical guide to their reduction in the diet. J. Am. Diet. Assoc. 110(6):911-916.

Vlassara, H., Brownlee, M. \& Cerami, A. (1985). High-affinity-receptor-mediated uptake and degradation of glucose-modified proteins: A potential mechanism for the removal of senescent macromolecules, Proc. Natl. Acad. Sci. USA. 82: 5588-5592.

Witz, G. (1989). Biological interactions of a, $\beta$-unsaturated aldehydes, Free Radical. Biol. Med. 7:333-349.

Wolff, SP., Jiang, ZY. \& Hunt, JV. (1991). Protein glycation and oxidative stress in diabetes mellitus and ageing, Free Radic. Biol. Med. 1(5):339-352.

Wu, X. \& Monnier, V.M. (2003). Enzymatic deglycation of proteins. Arch. Biochem. Biophys. 419:16-24.

Xue, M., Rabbani, N. \& Thornalley, PJ. (2011). Glyoxalase in ageing, Semin. Cell Dev. Biol. 22(3):293-301.

Yamagishi, S. (2011). Role of advanced glycation end products (AGEs) and receptor for AGEs (RAGE) in vascular damage in diabetes, Exp. Gerontol. 46(4):217-224.

Yamauchi, Y., Furutera, A., Seki, K., Toyoda, Y., Tanaka, K. \& Sugimoto, Y. (2008). Malondialdehyde generated from peroxidized linolenic acid causes protein modification in heat-stressed plants, Plant. Physiol. Biochem. 46(8-9):786-93. 
Yang, K., Feng, C., Lip, H., Bruce, W.R. \& O’Brien PJ. (2011). Cytotoxic molecular mechanisms and cytoprotection by enzymic metabolism or autoxidation for glryceraldehyde, hydroxypyruvate and glycolaldehyde, Chem. Biol. Interact. 191(1-3):315-21.

Yatscoff, RW., Tevaarwerk, GJM. \& MacDonald, JC. (1984). Quantification of nonenzymically glycated albumin and total serum protein by affinity chromatography, Clin. Chem. 30:446-449.

Yim, MB., Yim, HS., Lee, C., Kang, SO. \& Chock, PB. (2001). Protein glycation: creation of catalytic sites for free radical generation, Ann. N Y Acad. Sci. 928:48-53.

Havrilla, CM., Morrow, JD. \& Porter, NA. (2002). Formation of isoprostane bicyclic endoperoxides from the autoxidation of cholesteryl arachidonate, J. Am. Chem. Soc. 124:7745-7754.

Zimniak, P. (2008). Detoxification reactions: relevance to aging, Ageing Res. Rev. 7(4):281-300.

Zimniak, P. (2011). Relationship of electrophilic stress to aging. Free Radic. Biol. Med. 51(6):1087-10105. 


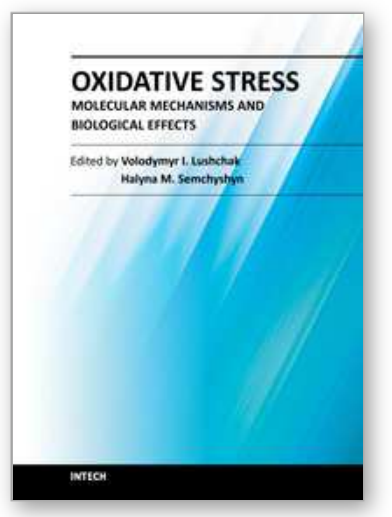

\author{
Oxidative Stress - Molecular Mechanisms and Biological Effects \\ Edited by Dr. Volodymyr Lushchak
}

ISBN 978-953-51-0554-1

Hard cover, 362 pages

Publisher InTech

Published online 25, April, 2012

Published in print edition April, 2012

Since the discovery of free radicals in biological systems researchers have been highly interested in their interaction with biological molecules. Denoted in 1980, and due to fruitful results and ideas, oxidative stress is now appreciated by both basic and applied scientists as an enhanced steady state level of reactive oxygen species with wide range of biological effects. This book covers a wide range of aspects and issues related to the field of oxidative stress. The association between generation and elimination of reactive species and effects of oxidative stress are also addressed, as well as summaries of recent works on the signaling role of reactive species in eukaryotic organisms. The readers will gain an overview of our current understanding of homeostasis of reactive species and cellular processes they are involved in, as well as useful resources for further reading.

\title{
How to reference
}

In order to correctly reference this scholarly work, feel free to copy and paste the following:

Halyna M. Semchyshyn and Volodymyr I. Lushchak (2012). Interplay Between Oxidative and Carbonyl Stresses: Molecular Mechanisms, Biological Effects and Therapeutic Strategies of Protection, Oxidative Stress - Molecular Mechanisms and Biological Effects, Dr. Volodymyr Lushchak (Ed.), ISBN: 978-953-51-0554-1, InTech, Available from: http://www.intechopen.com/books/oxidative-stress-molecular-mechanisms-andbiological-effects/interplay-between-oxidative-and-carbonyl-stresses-molecular-mechanisms-biological-effectsand-ther

\section{INTECH}

open science | open minds

\section{InTech Europe}

University Campus STeP Ri

Slavka Krautzeka 83/A

51000 Rijeka, Croatia

Phone: +385 (51) 770447

Fax: +385 (51) 686166

www.intechopen.com

\section{InTech China}

Unit 405, Office Block, Hotel Equatorial Shanghai

No.65, Yan An Road (West), Shanghai, 200040, China

中国上海市延安西路65号上海国际贵都大饭店办公楼405单元

Phone: +86-21-62489820

Fax: $+86-21-62489821$ 
(C) 2012 The Author(s). Licensee IntechOpen. This is an open access article distributed under the terms of the Creative Commons Attribution 3.0 License, which permits unrestricted use, distribution, and reproduction in any medium, provided the original work is properly cited. 